Pacific Northwest National Laboratory

Operafed by Battelle for the U. S. Bepartment of Energy

\section{A Discussion of SY-101 Crust Gas Retention and Release Mechanisms}

\author{
S. D. Rassat \\ P. A. Gauglitz \\ S. M. Caley \\ L. A. Mahoney \\ D. P. Mendoza
}

February 1999

$$
\begin{gathered}
\text { RECEIVED } \\
\text { MAR O5 } 1999 \\
\text { OSTI }
\end{gathered}
$$

Prepared for the U.S. Department of Energy under Contract DE-AC06-76RLO 1830 


\title{
DISCLAIMER
}

This report was prepared as an account of work sponsored by an agency of the United States Government. Neither the United States Government nor any agency thereof, nor Battelle Memorial Institute, nor any of their employees, makes any warranty, express or implied, or assumes any legal liability or responsibility for the accuracy, completeness, or usefulness of any information, apparatus, product, or process disclosed, or represents that its use would not infringe privately owned rights. Reference herein to any specific commercial product, process, or service by trade name, trademark, manufacturer, or otherwise does not necessarily constitute or imply its endorsement, recommendation, or favoring by the United States Government or any agency thereof, or Battelle Memorial Institute. The views and opinions of authors expressed herein do not necessarily state or reflect those of the United States Government or any agency thereof.

\author{
PACIFIC NORTHWEST NATIONAL LABORATORY \\ operated by \\ BATTELLE \\ for the \\ UNITED STATES DEPARTMENT OF ENERGY \\ under Contract DE-AC06-76RLO 1830
}

Printed in the United States of America

Available to DOE and DOE contractors from the Office of Scientific and Technical Information, P.O. Box 62, Oak Ridge, TN 37831 ; prices available from (615) $576-8401$.

Available to the public from the National Technical Information Service, U.S. Department of Commerce, 5285 Port Royal Rd., Springfield, VA 22161

This document was printed on recycled paper. 


\section{DISCLAIMER}

Portions of this document may be illegible in electronic image products. Images are produced from the best available original document. 


\section{A Discussion of SY-101 Crust Gads Retention and Release Mechanisms}

SD Rassat

PA Gauglitz

SM Caley

LA Mahoney

DP Mendoza

February 1999

Prepared for the U.S. Department of Energy under Contract DE-AC06-76RLO 1830

Pacific Northwest National Laboratory

Richland, Washington 99352 


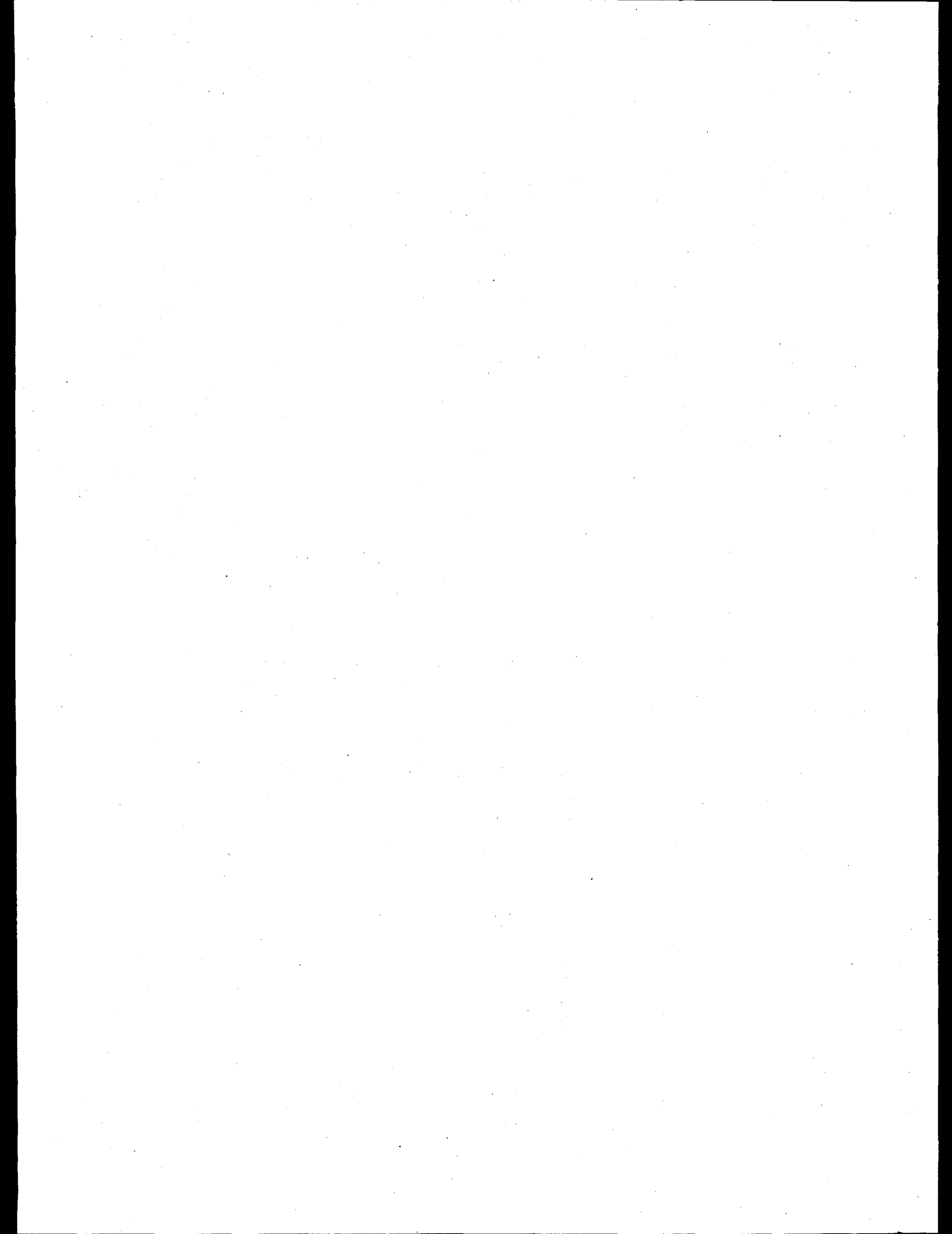




\section{Executive Summary}

The flammable gas hazard in Hanford waste tanks was made an issue by the behavior of double-shell Tank 241-SY-101 (SY-101). Shortly after SY-101 was filled in 1980, the waste level began rising periodically, due to the generation and retention of gases within the slurry, and then suddenly dropping as the gases were released. A mixer pump was installed in SY-101 in late 1993 to prevent gases from building up in the settled solids layer, and the large spontaneous gas releases have since ceased.

However, in recent years and especially in the last nine months, the surface level of waste in SY-101 has been increasing, and the level growth has shown significant and unexpected acceleration. Historically, level increases in SY-101 have been a good measure of retained gas and of changes in the retained gas. Based on a number of observations and measurements, including data from the void fraction instrument (VFI), we have concluded that the level growth is caused largely by increased gas retention in the floating crust. The crust contains between about 21 and $43 \%$ gas based on the most recent VFI measurements in the crust. Accordingly, it is important to understand the dominant mechanisms of gas retention, why the gas retention is increasing, and whether the accelerating level increase will continue, diminish, or even reverse. The retained gas in the crust is thought to be flammable, with hydrogen as a major constituent. This gas inventory poses a flammable gas hazard if it were to suddenly release. Previous evaluations of the hazards associated with crusts have assumed a more typical void of roughly $15 \%$ gas. The much higher void being observed in SY-101 represents essentially a new crust configuration, and the mechanisms for sudden gas release need to be evaluated.

Based on previous studies and theory, the gas in the crust should consist of particle-displacing bubbles that are retained due to the strength of the crust material. Three mechanisms of bubble migration through the crust are postulated: bubbles rising individually, bubbles connecting to an existing percolating pathway of connected gas bubbles, and individual bubbles migrating laterally under the crust and then coalescing to form a bubble sufficiently large to release through a weak region of the crust.

Perhaps the most significant prediction based on the existing bubble retention and release models is that the crust will reach a maximum gas fraction and will stop retaining additional gas. Previous studies have shown repeatedly that most waste materials have a characteristic maximum retained gas fraction that will not be exceeded. (A notable exception that must be considered is the possibility of forming stable froths or foams in which the gas fraction is considerably higher. Previously, stable froths were observed during gas retention experiments on samples of Tank 241AN-103 tank waste.) When bubbles readily coalesce and froth formation is not a concern, the maximum retention depends primarily on the waste strength where there are particle-displacing bubbles. For an assumed strength of 50 to $500 \mathrm{~Pa}$, which is the expected range for the crust material in SY-101, the maximum gas retention should vary from 30 to $50 \%$. As the void fraction in the crust approaches this maximum retention, it is expected that the rate of waste level rise will diminish and that the waste level will eventually reach a maximum. 
In September 1998, an average $\sim 30 \%$ void in the crust was estimated, and a surface level of 418 inches was reported. By December 1998, the surface level had increased to $\sim 425$ inches, and the crust was estimated at $\sim 70$-inches $(1.8-\mathrm{m})$ thick with an average void of $\sim 35 \%$. If the crust increases to a maximum of about $50 \%$ void, the level will rise an additional 20 inches (neglecting additional rise due to increased crust buoyancy). Thus the maximum attainable level in SY-101 should be about 445 inches, assuming other mechanisms of gas retention remain unchanged. This also assumes that the crust continues to increase in void without having additional solids added to the crust. However, the most recent analysis suggests crust thickness may be increasing due to both mass addition and changes in retained gas fraction. Growth by both mechanisms may ultimately lead to waste levels greater than 445 inches.

The physical configuration of the crust dictates the mechanisms of gas retention and release and the magnitude of plausible gas releases from the crust layer. Based on visual evidence and VFI void and "strength" data, we have proposed a conceptual crust model. In this model, the middle to the top of the crust is stronger, drier, and lower in gas fraction than the lower crust. In addition to these vertical variations (crust layering), the crust is likely inhomogeneous laterally as well. The SY-101 crust is thought to consist of individual floating "original" waste bergs, separated or only loosely adhered at vertical vents and fissures by much weaker "fresh" crust.

While this is the proposed SY-101 crust model, a range of crust configurations is possible. The unique gas retention and release scenarios resulting from these configurations are postulated, and the configurations are discussed according to the degree of vertical and lateral homogeneity in the crust properties. Gas retention and release mechanisms applicable in homogeneous crust materials may also be pertinent in heterogeneous crusts. Individual bubble rise and gas migration through percolation pathways are two mechanisms of gas release that are generally applicable to all crust configurations. These mechanisms are expected to result in semi-continuous but relatively small gas releases through the crust that are dependent on the crust strength and gas fraction. In a homogeneous, bubble-laden crust, the rise of an individual bubble could initiate a cascade of bubbles leading to local gas releases on the order of cubic meters $\left(1 \mathrm{~m}^{3}\right.$ is $\left.35 \mathrm{ft}^{3}\right)$. The size of the bubble-cascade releases depends on the local gas fraction, bubble size, and the crust thickness.

The presence of lateral heterogeneities such as vents and fissures in a crust leads to additional release scenarios. Established crust openings provide pathways for the direct release of bubbles that float up to the opening and may lead to release of gas through lateral migration (percolation) of bubbles to the fissure or vent. Existing or newly created crust openings may also be the preferred release pathway for larger bubble pockets and pooled bubbles. A bubble pocket may form within the crust at the interface of a relatively strong layer atop a weaker layer. Individual bubbles reaching the interface may coalesce into larger bubbles that spread laterally and eventually release to a crust opening. Similarly, pooled bubbles may form at the bottom of the crust surface, fed by bubbles generated in the bulk of the waste below. Depending on the geometry, the bottom crust surface may act as an inverted pool that traps gas until a bubble overflows the pool boundaries and spills out through a crust opening. Additional investigation is necessary to determine the potential size of pooled bubbles, bubble pockets, and gas releases associated with them. Preliminary experimental results support the importance of the pooled bubble mechanism. 
The laterally and vertically heterogeneous SY-101 crust may contain a series of floating waste bergs. These bergs potentially have a higher gas content and lower density at the bottom than near the top surface. If a berg has a relatively broad base, it is expected to be stable, but bergs that are only as wide as or narrower than their height are likely to be unstable. These bergs may be susceptible to capsizing with at least partial gas release. For a single crust waste berg cube $\sim 1.8 \mathrm{~m}$ on a side and initially at 0.35 gas fraction, capsizing produces a gas release of about $2 \mathrm{~m}^{3}$ $\left(70 \mathrm{ft}^{3}\right)$ if all gas is released.

In addition to the "natural" gas release mechanisms in the various crust configurations, other external forces may lead to sudden gas releases from the SY-101 crust. These include crust gas releases resulting from wetting of the crust top, crust disruption in waste transfer, intrusion through the crust, and earthquakes. Both the magnitude and rate of gas release may differ in these release scenarios, with earthquakes most likely to produce the largest sudden release. Wetting the crust surface with a widespread but minimal volume of water (e.g., fine water spray) or humidification is likely to release gas from the crust and will ultimately lead to modification of the retention and release properties of the crust. In such an approach; the rate of gas release may potentially be controlled if the dissolution kinetics are understood. Partial dissolution of the topmost crust may lead to a less stable configuration with a more dense, gas-free slurry on top of a bubble-laden crust layer.

Localized, small-area intrusions through the crust, including core sampling and water lancing (localized wetting), are not expected to result in large gas releases from the crust. During these intrusions, gas may be released directly from the disturbed crust and through lateral percolation from a relatively small area adjacent to the disturbance. In addition, bubble pockets or pooled bubbles may be tapped during the intrusion, leading to the release of gas from those sources.

Retrieval of convective waste from below the crust surface may also disrupt the crust. Most likely, some fraction of crust would remain attached to the tank wall or other tank equipment as the convective layer recedes. At a minimum, this will result in modest gas releases from the shear zone between the attached and floating crust. In a more extreme scenario, crust bergs at the periphery of the new floating layer might roll outward, pushed by leaning bergs in the center of the tank. This would potentially lead to gas releases larger than would be caused by the capsizing of a single waste berg. These releases are still most likely smaller than those resulting from an earthquake, because in the earthquake scenario the shearing forces may be considerably more substantial.

Earthquakes might result in large, rapid gas releases from the SY-101 crust. A minimal seismic event resulting in only partial gas release from the entire crust, for instance, from an initial 0.35 void fraction to a final of 0.25 , corresponds to a significant $97-\mathrm{m}^{3}\left(3400-\mathrm{ft}^{3}\right)$ release. This hypothetical release is nearly equivalent to the last major gas release $\left(-2200 \mathrm{ft}^{3}\right)$ from SY-101 in August 1993.

Initial experimental observations of gas retention and release in floating crusts composed of waste simulants support the expected behavior. In the experiments conducted, floating crusts were created from simulants made buoyant by incorporating gas bubbles. Gas bubbles were then 
introduced from below the crust by sparging. In a case of a relatively strong crust, thousands of bubbles coalesced into a single large bubble before it could breach the crust. Once the release pathway was formed, however, much smaller bubbles were capable of releasing through the pathway. For experiments with a different but relatively weaker crust, the same general behavior was observed, but fewer bubbles needed to coalesce to make a single bubble large enough to breach the crust.

The results presented here are preliminary conclusions and predictions of expected behavior. Further studies are needed to confirm and test the validity of these results. 


\section{Acknowledgments}

We thank Chuck Stewart for his persistent encouragement to take on this SY-101 crust gas retention and release analysis, for his insight into the crust configuration and physics, and for providing late-breaking estimates of the SY-101 crust properties.

We also acknowledge the quality support of our editor Sheila Bennett for her assistance with this report as well as the preceding letter report. 



\section{Contents}

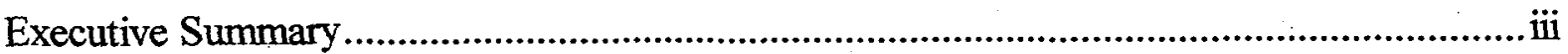

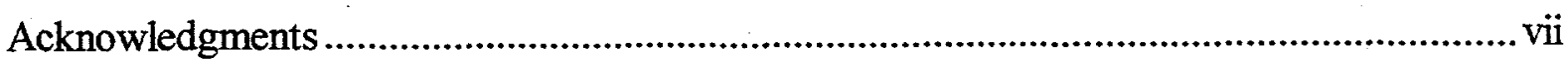

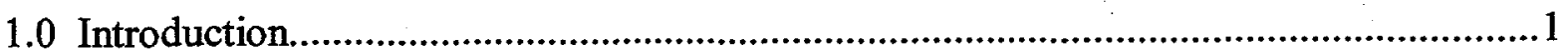

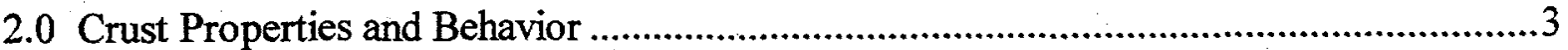

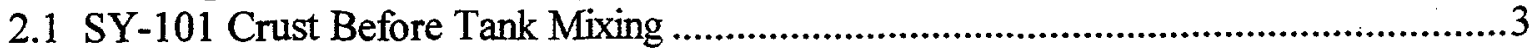

2.2 SY-101 Crust after Tank Mixing.......................................................................4

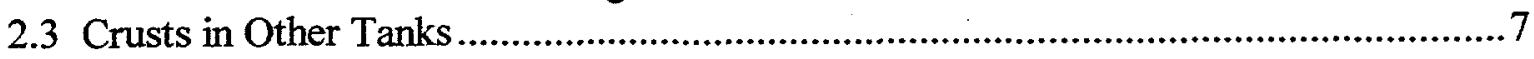

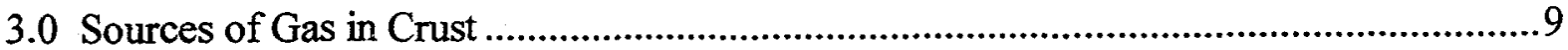

4.0 Mechanisms of Gas Retention and Release..................................................... 13

5.0 Gas Retention and Release in Various Crust Configurations.....................................17

5.1 Vertically Homogeneous Crust ....................................................................... 17

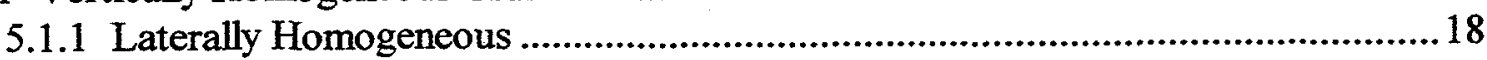

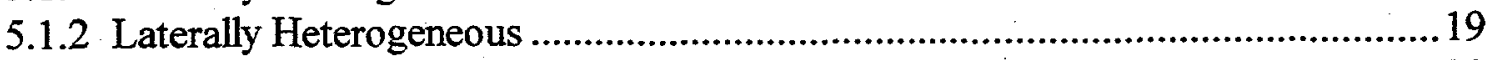

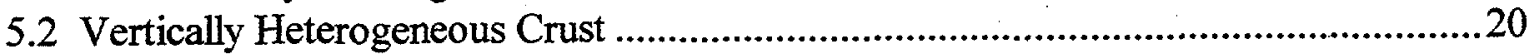

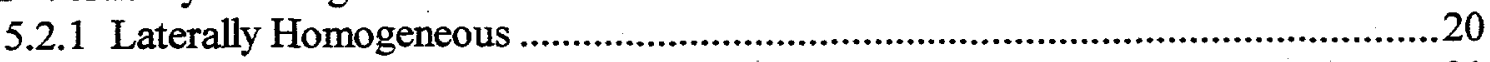

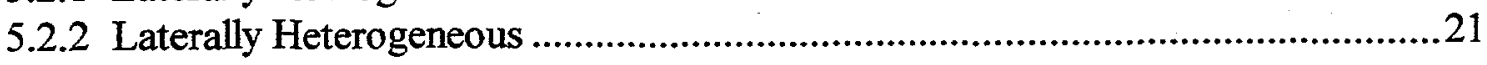

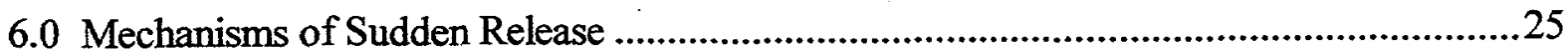

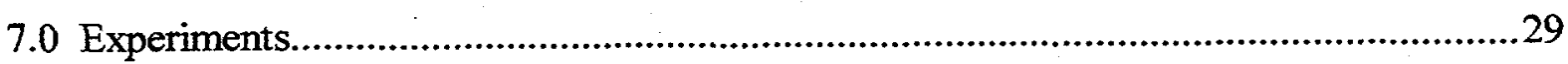

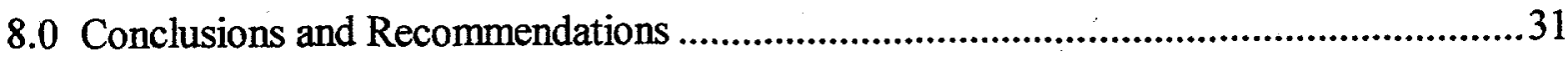

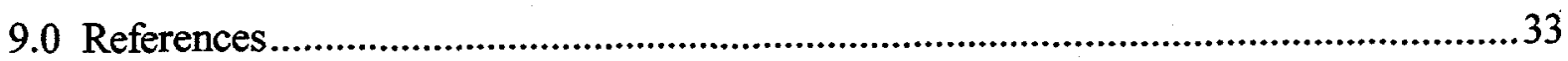

Appendix: Summary of Crust Workshop, May 28, 1997 ............................................1 


\section{Figures}

2.1 SY-101 Crust Growth from 1995 through 1998 6

3.1 Mechanisms of Gas Movement to the Bottom of a Floating Crust....................................10

4.1 Mechanisms of Gas Migration Through a Floating Crust.....................................................15

5.1 Schematic of Proposed SY-101 Crust Configuration..........................................................18

5.2 Variation in Crust Thickness (solid line) with Crust Void Fraction and the Effect on Gas Release Volumes for Capsizing Single Wasteberg Cubes

6.1 Variation in Crust Thickness with Crust Void Fraction and the Effect on Gas Release Volumes for Global Release Throughout the Crust Layer.

7.1 Bubble Coalescence and Release During PMMA Simulated Crust Experiment 30 


\subsection{Introduction}

The flammable gas hazard in Hanford waste tanks was made an issue by the behavior of double-shell Tank (DST) 241-SY-101 (SY-101) ${ }^{(a)}$ Shortly after SY-101 was filled in 1980, the waste level began rising periodically, due to the generation and retention of gases within the slurry, and then suddenly dropping as the gases were released. An intensive study of the tank's behavior revealed that these episodic releases posed a safety hazard because the released gas was flammable, and, in some cases, the volume of gas released was sufficient to exceed the lower flammability limit (LFL) in the tank headspace (Allemann et al. 1993). A mixer pump was installed in SY-101 in late 1993 to prevent gases from building up in the settled solids layer, and the large episodic gas releases have since ceased (Allemann et al. 1994; Stewart et al. 1994; Brewster et al. 1995).

However, the surface level of SY-101 has been increasing since at least 1995, and in recent months the level growth has shown significant and unexpected acceleration. Based on a number of observations and measurements, including data from the void fraction instrument (VFI), we have concluded that the level growth is caused largely by increased gas retention in the floating crust. In September 1998, the crust contained between about 21 and $43 \%$ void based on VFI measurements (Stewart et al. 1998). Accordingly, it is important to understand the dominant mechanisms of gas retention, why the gas retention is increasing, and whether the accelerating level increase will continue, diminish, or even reverse.

It is expected that the retained gas in the crust is flammable, with hydrogen as a major constituent. This gas inventory would pose a flammable gas hazard if it were to release suddenly. In May 1997, the mechanisms of bubble retention and release from crust material were the subject of a workshop. ${ }^{(b)}$ The evaluation of the crust and potential hazards assumed a more typical void of roughly $15 \%$ gas. It could be similar to percolation in single-shell tank (SST) waste forms. The much higher void being currently observed in SY-101 represents essentially a new crust configuration, and the mechanisms for sudden gas release need to be evaluated.

The purpose of this study is to evaluate the situation of gas bubbles in crust based on the previous work on gas bubble retention, migration, and release in simulants and actual waste. We have also conducted some visual observations of bubble migration through simulated crusts to help understand the interaction of the various mechanisms.

(a) Underground waste storage tanks at Hanford are designated with the prefix 241-. In this report the 241 - is omitted, as it is in common usage.

(b) A summary of this workshop written by GD Johnson is presented in the appendix to this report to document earlier views on crusts. A further reference to the workshop can be found in a letter from BC Hudson to J Kinzer (DOE-RL) dated June 16, 1997: "Re: 27th CRS Meeting May 28-30, 1997," which includes CRS comments on the Crust Workshop. 
In Section 2, the behavior and properties of SY-101 and other crusts are discussed. In Section 3, the sources of the gas in the crust are presented. Particular emphasis is placed on the mechanisms controlling the type of bubbles arriving at the bottom of the crust and the role of in situ gas generation within the crust. Section 4 contains a discussion of bubble retention and release mechanisms. A number of previous studies have investigated bubble behavior, and we summarize the pertinent background material and extrapolate to the expected behavior of bubbles in crust. This is a broad discussion of likely mechanisms; subsequent sections discuss the relative importance of each mechanism for various crust configurations. Section 5.1 discusses behavior in homogeneous crust with and without vertical fractures, and Section 5.2 considers the complication of layering. In Section 6 are comments on mechanisms of sudden release that were not covered specifically in other sections, and experimental observations are described in Section 7. Section 8 contains our conclusions, and cited references are located in Section 9. A summary of the workshop on bubble retention in crusts is the subject of the appendix. 


\subsection{Crust Properties and Behavior}

Most of the gas that has accumulated in SY-101 since pump-mixing operations began in July 1993 is believed to be stored in the $\sim 1.8$-m-thick floating crust. This situation raises the question of whether the crust properties have changed since pumping began, because those properties may have a bearing on the increased gas retention. This section presents an overview of what is now known about crusts in Hanford waste tanks. Section 2.1 reviews information on the SY-101 crust prior to tank mixing; Section 2.2 presents the available information on the current $S Y-101$ crust properties; and Section 2.3 summarizes our knowledge of crusts in other Hanford tanks.

No measurements were made of the gas volume fraction in the SY-101 crust before pump mixing operations. Core samples were taken before mixing, however, and the composition of the crust was found to be similar at several different risers. In addition, the crust composition was found to be much the same as that of the bottom, nonconvective layer. Crust samples were also visibly wet. Both the uniform composition and the wetness of the crust (which was also visible in videos) may have resulted from the frequent submergence of the crust by gas release events (GREs). Since pumping began and the GREs ended, the crust has become dryer in appearance. Its shear strength is less at the bottom of the crust than in the middle. The VFI recently measured the crust's gas volume fraction as higher at the bottom (0.43) than in the middle $(0.21$ to 0.30 ; Stewart et al. 1998). These current gas fraction measurements are higher than the estimates for the pre-mixing crust. Section 5 contains a drawing of how the crust is believed to look (in September 1998); this schematic is based on our knowledge and assumptions of how the crust has changed over time and how gas is delivered to the crust, retained in the crust, and released from the crust.

\subsection{SY-101 Crust Before Tank Mixing}

Little is known about the properties of the crust in SY-101 before pumping began. The chemical composition of the crust was found to be rather uniform across the crust and very similar to the composition of the composite bulk samples from the nonconvective layer(Herting 1992a). The GREs in SY-101 often broke up and submerged the crust, a process that may have contributed to its homogeneity. However, the crust thickness showed no detectable changes as a result of the GREs. ${ }^{\text {(a) }}$ The last recognized surface motion occurred in November 1993 as a result of a gas release during initial mixing of the nonconvective layer. The surface is described as appearing progressively "drier" since that time (Stewart et al. 1996a).

Auger, sludge weight, and core samples were taken during Window C (May 20 to 24, 1991), shortly after a GRE on May 16, 1991 (Herting 1992a). The eight gallons of water used to soften the crust compromised the crust layer core samples. Of the three crust core samples, only segment 2 contained solids, which are the consistency of mud, and those only in small quantity. Of the four Window $\mathrm{C}$ augers, three contained very little sample; the riser $13 \mathrm{~A}$ auger sample was

(a) Crust thickness can be determined only from temperature profiles at the multifunction instrument trees (MITs). The process is accurate to within \pm 6 inches at best. 
"very wet and soupy," the riser 11A sample was "quite wet," and the riser 16A sample was "grainy and crumbly." The fourth auger sample (from riser 22A) was crumbly in the upper portion and pasty in the lower portion. The sludge weight samples ranged from quite wet (riser $13 \mathrm{~A}$ ) to cement-like (risers $11 \mathrm{~A}$ and $16 \mathrm{~A}$ ) to very hard (video observations showed that the sludge weight was not able to penetrate the surface at riser $22 \mathrm{~A}$ ). However, all the crust samples were similar in chemical composition, with very consistent organic carbon content. Differences in the appearance of the samples were largely the result of different moisture content.

The auger sample from riser $22 \mathrm{~A}$ (Window $\mathrm{C}$ ) was found to have a bulk (gas-free) density of $1.77 \mathrm{~g} / \mathrm{mL}$ and to contain 96 vol\% centrifuged solids. ${ }^{(a)}$ The shear strength of the material was measured using a shear-vane viscometer and found to be $4,200 \mathrm{~Pa}$ at $50^{\circ} \mathrm{C}, 210 \mathrm{~Pa}$ at $65^{\circ} \mathrm{C}$, and $270 \mathrm{~Pa}$ at $80^{\circ} \mathrm{C}$. At the higher temperatures, the shear strength of the crust sample was lower than many of the values measured in the nonconvective slurry.

Core samples were also taken from the crust during Window E (December 14 to 16,1991 ) after a vigorous GRE on December 4, 1991. As was the case for Window C, the core samples from the Window E crust were compromised by water addition (Herting 1992b). Little information on the crust was obtained from Window $\mathrm{E}$.

No gas volume fraction measurements were made on the crust before pumping. The gas volume fraction required to make the crust buoyant was calculated to be $0.16 \pm 0.1$, corresponding to an in situ gas volume of $62 \pm 41 \mathrm{~m}^{3}$ (Meyer et al. 1997). This value was based not on measurement but on buoyancy and other mechanical considerations. In one related observation, polarized light microscopy showed that some of the samples that were very dry when received (including the Window C riser 22A sludge weight sample from the crust) contained gas-trapping "sponge" particles (Herting 1992a). These were aggregates of 1- $\mu \mathrm{m}$ needles that held gas bubbles within the aggregate. The arrangement was described as analogous to the snowflakes in a snowball. Thus, the gas content of the crust may not have been solely in macroscopic form.

As of April 1995, the crust thickness was measured (from MIT validation probe temperature profiles) at $102 \pm 10 \mathrm{~cm}(40 \pm 4 \mathrm{in}$.) at riser $17 \mathrm{~B}$ and $76 \pm 10 \mathrm{~cm}(30 \pm 4 \mathrm{in}$. $)$ at riser $17 \mathrm{C}$. At that time, the crust had not changed measurably since July 1994, and the waste level was $1020 \mathrm{~cm}$ (Stewart et al. 1996a).

\subsection{SY-101 Crust after Tank Mixing}

As a result of mixer pump operations, the crust has not been broken or disturbed by large GREs since November 1993. This is a substantially longer dryout period than the crust had previously experienced (the time between GREs was only three to five months). A change in the moisture content and moisture distribution of the crust might be expected to result. If so, the crust properties would also have changed, judging by the strong variation in crust properties with moisture that was observed in Window $\mathrm{C}$ crust samples.

(a) Tingey JM. February 1992. "Physical Characterization of Tank 101-SY Core Samples from Window C." Pacific Northwest Laboratory, Richland, Washington. 
Gas volume fractions in the lower half of the crust were measured in June and September 1998 using the VFI (Stewart et al. 1998). The first crust gas volume fraction was measured at riser $11 \mathrm{~B}$ on June $29,1998,12$ to 18 hours after a pump run aimed at that riser, at a location 31 inches below the waste surface. Further VFI measurements were made on September 11, 1998 , at riser 1C, about 14 hours after a pump run aimed at the riser. The VFI arm was rotated to take each sample at a different azimuth. Gas volume fractions of 0.21 to 0.43 were measured in the lower half of the crust. The highest gas content appeared to be at the bottom of the crust, decreasing upward. An average crust gas fraction of 0.30 was estimated from the VFI results. VFI motion in the crust did not cause a significant gas release, though a "considerable" amount of bubbling was observed during the June 29 experiment.

Although the VFI could be raised and lowered in the lower half of the crust with its arm extended, above a certain point the resisting force made further upward motion impossible. The force was $1600 \mathrm{lb}$ at the bottom of the crust (approximate weight of the VFI) but increased to $2000 \mathrm{lb}$ (the limit for the VFI) about halfway up into the waste layer. The crust strength, like the gas volume fraction, is apparently not vertically uniform.

The elevations of the top and the base of the crust have both changed since April 1995, indicating a change in the thickness and the "freeboard" of the crust. As determined from the VFI experiments in the summer of 1998, the thickness had increased by about 14 inches to 54 inches. The base elevation (derived from temperature profiles and by contact resistance of the VFI arm) was lower by only three to four inches (Stewart et al. 1998), meaning that more of the crust is above the free liquid level than in 1995. This extra buoyancy is probably the result of a higher gas volume fraction in the crust. At the end of June 1998, the crust freeboard was estimated to be 12 inches, based on the assumption that the level measured by the riser 1C Enraf gauge was the free liquid level (Stewart et al. 1998).

As shown in Figure 2.1, a December 1998 analysis indicates that the crust thickness and the freeboard are continuing to increase.$^{(a)}$ The figure includes a four-year history of crust level data and demonstrates an apparent acceleration in crust thickness in 1998. The crust top (total waste) and liquid elevations in the figure were estimated from the riser 1A and riser 1C Enraf level gauges, respectively. The crust top data were "smoothed" from present to past by removing step changes due to calibrations of the level gauge. The liquid level data were taken as the minimum level registered five to ten days after a water flush at the riser $1 \mathrm{C}$ gauge. The curve through the liquid level data is the best fit of the individual readings. As described in Stewart et al. (1998), the crust base elevation data are estimated from waste temperature profiles measured with an MIT validation probe. The crust base elevation data points shown in Figure 2.1 were obtained from temperature profiles at both risers $17 \mathrm{~B}$ (filled squares) and $17 \mathrm{C}$ (open squares), while the curve represents a fit to all the data. The crust thickness is calculated as the difference in crust top and crust base elevations.

(a) Stewart CW. December 22, 1998. Data provided in a personal communication to SD Rassat, Pacific Northwest National Laboratory, Richland, Washington. 


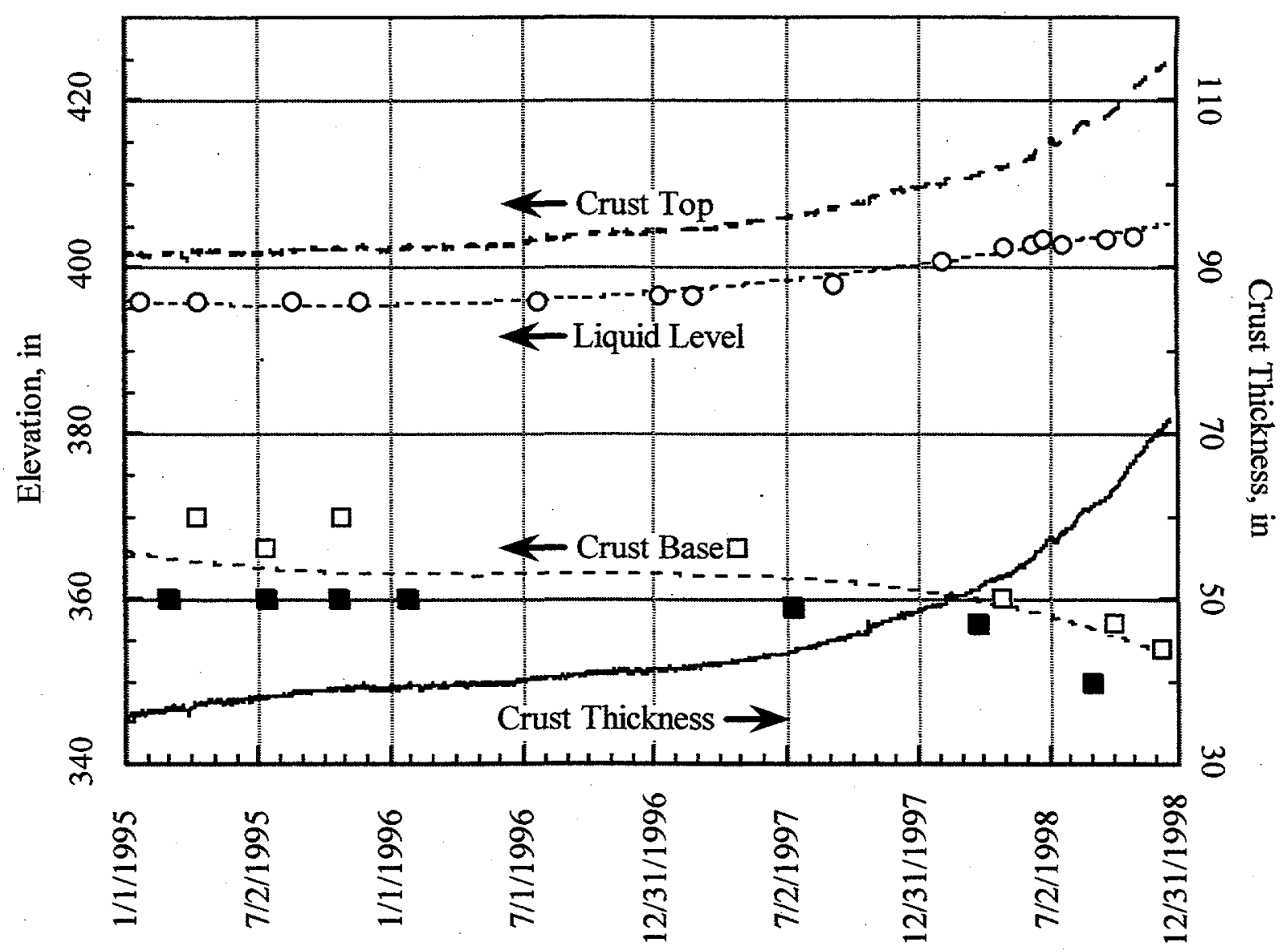

Figure 2.1. SY-101 Crust Growth from 1995 through 1998 (dashed lines, elevation axis; solid line, thickness axis)

The current estimate of crust thickness, $\sim 70$ inches (Figure 2.1 ), is substantially greater than the Stewart et al. (1998) estimate of $\sim 54$ inches available at the time of initial writing of the present document. The increase in thickness is thought to be due to both an increase in bulk average gas fraction in the crust and the addition of crust mass. The level data in Figure 2.1 were used in a buoyancy model to estimate the average gas fraction in the SY-101 crust in midDecember 1998 at $\sim 0.36 .{ }^{\text {(a) }}$ The same analysis provided an average crust void fraction estimate of $\sim 0.30$ in September 1998, in good agreement with that estimated from VFI data (Stewart et al. 1998).

In addition to increased gas retention, the crust is believed to have grown over time from the bottom by a process of solids accumulation. The crust mass accumulation may be supplied by mechanisms ranging from the agglomeration of small particles coating "armored" bubbles to the accretion of large "gobs" floating up from the tank bottom layer of solids. If bottom-up growth

(a) Stewart CW. December 22, 1998. Data provided in a personal communication to SD Rassat, Pacific Northwest National Laboratory, Richland, Washington. The Enraf level data were originally obtained from the TWINS database. 
has occurred, then the bottom of the crust might be different in structure and properties than the upper crust that existed prior to pumping, the upper crust having been subjected to GRE-related mechanisms, lower temperatures, and potential dryout due to ventilation.

\subsection{Crusts in Other Tanks}

Samples have been taken from other Hanford tanks with floating high-solids waste layers, and a discussion of these measurements and comparison with SY-101 is in order. DSTs AW-101 and AN-103 have crusts about 30 inches thick, as did SY-101 before pumping. The crust in DST SY-103 is considerably thinner.

GREs in Tanks SY-103, AW-101, and AN-103 cause only small level changes, and crust disturbances, if any, are much less than in SY-101. Tanks AW-101 and AN-103 have been sampled using the retained-gas sampler (RGS) and have also undergone VFI measurements, although crust samples were not always measured (Shekarriz et al. 1997; Stewart et al. 1996a). VFI, but not RGS, measurements were obtained in Tank SY-103; however, the crust was not tested directly (Stewart et al. 1996a).

Meyer et al. (1997) estimated an in situ gas volume in the SY-103 crust of only $6 \pm 4 \mathrm{~m}^{3}$. This corresponds to a gas volume fraction of $0.08 \pm 0.04$ in the 8-inch-thick crust. An auger sample of SY-103 crust at riser 7A was described as hard, dry, and brittle, and the top-most portion of a sample at riser 22A was described as white and crusty (Bell 1994). These visual observations correspond well with the very low moisture contents (8-15\%) of these samples reported in the same study. Higher moisture content (24-33\%) was reported for the other fractions of the riser 22A sample and an auger sample from riser 14B (Bell 1994).

The moisture content of the top of the AW-101 crust (obtained from 1995 auger samples at risers 12A, 13A, and 24B) was 34 to $42 \mathrm{wt} \%$ (Baldwin 1995). The values are consistent with the wet sludge appearance of segments 1 and 2 of the cores taken at risers 24A and 24B in 1996 and with the moisture content measured in those segments (Benar 1996). The extrusion photos for the crust segments show a broken-up appearance resembling that of bentonite clay simulant with shear strength of 100 to $200 \mathrm{~Pa}$ (Gauglitz and Aikin 1997). This strength is slightly greater than that estimated from extrusion videos for cores from the nonconvective layer under riser $24 \mathrm{~A}$ in AW-101.

The void fraction in the AW-101 crust was not measured by RGS or VFI. Meyer et al. (1997) estimated an in situ gas volume in the crust of $36 \pm 15 \mathrm{~m}^{3}$, or a gas volume fraction of 0.15 \pm 0.05 in the 24-inch-thick crust. The gas-free densities of the crust and convective layers were nearly equal at 1.6 to $1.8 \mathrm{~g} / \mathrm{mL}$, according to core sample measurements (Baldwin 1995); however, it is suspected that the convective layer sample may have contained suspended solids because the density is unusually high. Meyer et al. (1997) report a mean convective layer density of $1.43 \mathrm{~g} / \mathrm{mL}$, which was determined from ball rheometer measurements.

Crust core samples from AN-103 consisted of segments 1 from risers 12A and 21A described as wet or moist salt (Wilkins et al. 1997). The lower half of segment 12A-1 (probably no more 
than seven inches down into the crust) had a moisture content of $32 \mathrm{wt} \%$. A core extrusion photo of segment 21A-1 provided by Meyer et al. (1997) shows a single unbroken extrusion. Therefore, segment $21 \mathrm{~A}-1$ had a strength of $500 \mathrm{~Pa}$ or more based on comparisons with bentonite clay simulant extrusions (Gauglitz and Aikin 1997). This strength compares with strengths estimated from extrusion videos for cores from the nonconvective layer under riser 21A. Pock marks on the side of the 21A-1 extrusion suggest that some of the gas was present as bubbles large enough to be visible.

One RGS sample was taken in the 36-inch-thick crust of AN-103: segment 2 from riser 12A. The center of this 19-inch sample was about 16 inches below the waste surface, so the sample was entirely within the crust. Hydrogen made up $63 \mathrm{~mol} \%$ of the crust sample gas and an average of $62 \mathrm{~mol} \%$ of the nonconvective layer gas (Shekarriz et al. 1997). The gas volume fraction in the RGS crust sample was found to be 0.15 , with a gas composition nearly the same as that in nonconvective layer samples. The gas-free bulk density of segment 21A-1 was $1.70 \mathrm{~g} / \mathrm{mL}$, compared with specific gravity of 1.4 to 1.5 for the drainable liquid from convective layer samples. Given these densities, the measured gas volume fraction is just enough to make the crust buoyant.

Tank A-101, a single-shell tank, contains a floating layer about 170 inches thick that floats on a dense layer of liquid of about the same thickness. Though the floating layer in A-101 is too thick to qualify as a crust, certain of its properties may be relevant to the SY-101 crust. RGS sampling (Shekarriz et al. 1997) found gas volume fractions from 0.12 to 0.18 , with the gas volume fraction consistently decreasing from the bottom of the layer to the top. X-rays of these samples showed bubbles ranging from small $(1 \mathrm{~mm})$ to large enough to span the 1.125 -inch diameter of the sampler. The hydrogen content of the gas was constant (within scatter) over the layer. There is no evidence to support a higher hydrogen fraction at the top of the layer (segment 2). A mixed sample from the center of the layer (segment 5) had a shear strength (measured with a shear-vane viscometer) of $640 \mathrm{~Pa}$ (Rassat et al. 1998). Note that the shear undergone by this sample during mixing almost certainly lowered its measured shear strength from the original value. 


\subsection{Sources of Gas in Crust}

The physical state of a crust is influenced by many factors, including the mechanisms of crust formation and crust evolution. Understanding these factors may be key to developing an understanding of gas retention and release in crust. The means by which gas is delivered to the crust is an important consideration. The three main categories of gas supply to the crust are in-crust generation, gas bubble convection to the lower crust surface, and convection of gas-saturated liquid to the lower crust surface. These crust gas supply mechanisms are generally applicable to all tank wastes, but some of the mechanisms are more dominant in SY-101 because of jet mixer pump operation.

A small fraction of the gas generated in SY-101 is likely produced within the liquid contained in the crust layer. To evaluate the importance of generation within the crust, the fraction of tank liquid held up in the crust must be estimated. Recent analysis indicates $\sim 0.36$ gas fraction in the $\sim 70$-inch (1.8-m)-thick crust layer (see discussion of Figure 2.1 in Section 2.2). It is assumed that the remainder of the crust volume is evenly split between liquid and solid components $(\sim 30 \%$ each by volume). This gives a liquid height equivalent of $\sim 21$ inches $(0.5 \mathrm{~m})$ in the crust compared with a $\sim 354$-inch (9.0-m)-thick convective layer, assumed to be $75 \%$ liquid, below the crust. Therefore, only about $9 \%$ by volume of the liquid is in the crust, and at a maximum, $9 \%$ of the gas generation occurs in the crust. Crust dryout and the lower average temperature and lower dose rate of the crust relative to the bulk waste all tend to reduce the fraction of gas generated in the crust.

If only $9 \%$ or less of the gas is generated in the crust, greater than $91 \%$ of the gas generated in SY-101 reaches the crust from below and is either retained in the crust or passes through it to the tank headspace. Gas is delivered to the crust bottom dissolved in liquid or as preformed bubbles. Gas, liquid, and solids are all convected to the crust bottom during a pump run. When liquid containing dissolved gas species (e.g., hydrogen) is circulated in the tank, packets of gas-saturated or partially gas-saturated liquid are moved from tank depths to the lower crust surface. Because of the reduced hydrostatic load at the crust bottom, many of these convected liquid elements may be slightly supersaturated with gas species. Gas, in the form of bubbles, can then be supplied to the crust through the exsolution of liquid-dissolved gas species into existing gas bubbles at the crust/convective-layer interface, or new gas bubbles may be nucleated on solid particles during or after transit of the liquid element.

Figure 3.1 shows the expected configurations of existing gas bubbles floating up to the bottom of the SY-101 crust through the action of the mixer pump or natural gas releases. The gas can arrive as individual bubbles that have detached themselves from the solid particles of the waste. The bubbles can also arrive with solid waste particles. In one case, gobs of bubbly waste may rise from the layer of settled solids without the bubbles disengaging. It is also anticipated that some of the bubbles will rise with a coating of particles, which is commonly referred to as armored bubbles. In comparison to the individual bubbles, the armored bubbles do not readily coalesce because the solids coating inhibits close contact between bubbles. 

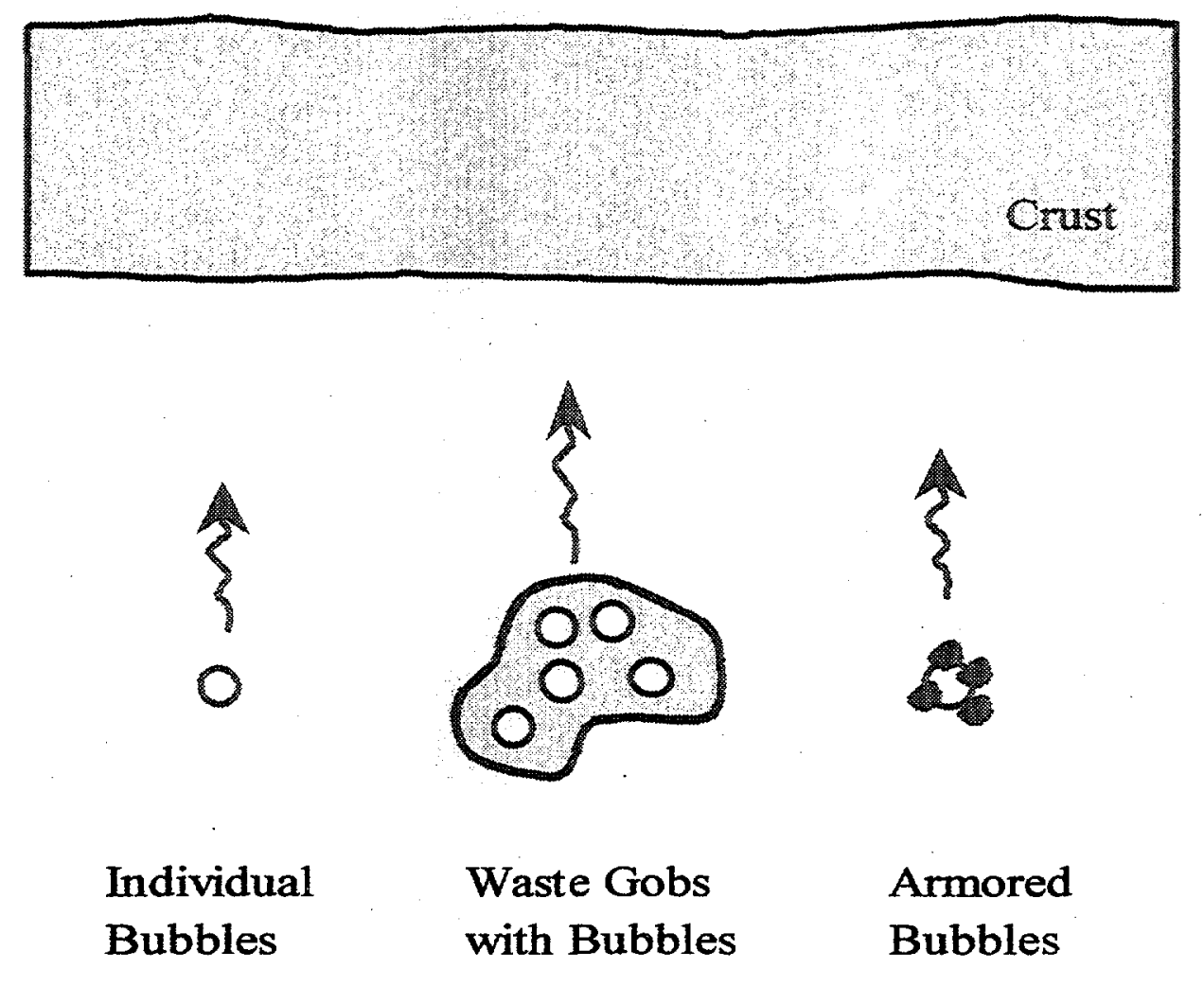

Figure 3.1. Configurations of Gas Moving to the Bottom of a Floating Crust

It is unlikely that bubbles larger than a few centimeters will arrive at the crust from below. First, bubbles larger than about $1 \mathrm{~cm}$ are not expected in the settled solids because waste strong enough to retain such bubbles will force the bubbles to be dendritic (Stewart et al. 1996b), and it is unlikely that a dendritic bubble would release as a spherical bubble without breaking up. And images of extruded cores generally show dimples indicative of bubbles less than a centimeter in diameter (Meyer et al. 1997). Finally, bubbles larger than a few centimeters may be reduced in size by breakup mechanisms that occur when the bubbles rise from the settled solids layer through the convective region. (While breakup of several-centimeter bubbles rising in water is known [Levich 1962], this mechanism is less likely in viscous tank waste.) Accordingly, the bubbles arriving at the bottom of the crust are expected to be approximately one centimeter and smaller.

Figure 3.1 depicts configurations of existing gas bubbles that could be convected to the crust bottom. It does not seek to portray the other noted gas sources (in-crust generation and convected gas-saturated liquid), nor does it accurately depict the expected heterogeneous crust configuration. For example, if solids are deposited from the bottom up, as in the waste gobs and armored bubble configurations, we expect the crust to be weaker and moister on the bottom than on the top. The overall crust configuration is a function of the configuration(s) of gas delivered to the crust, the mechanism(s) of gas retention in (and adjacent to) the crust, and the mechanisms of gas migration and release through the crust. Mechanisms of gas retention, migration, and 
release in crust are discussed in Section 4. A more complete picture of the current SY-101 crust is depicted in Section 5 with a discussion of possible SY-101 crust gas retention and release scenarios. 


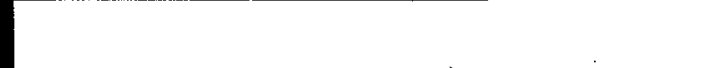




\subsection{Mechanisms of Gas Retention and Release}

Gas bubble retention and release mechanisms of potential importance in Hanford wastes have been the subject of studies by Gauglitz et al. (1994, 1995, 1996), Rassat et al. $(1997,1998)$, Bredt et al. (1995), and Bredt and Tingey (1996). These studies have focused on bubbles generated in situ and retained in the settled solids layers of waste tanks. The conditions pertaining to crusts where gas bubbles arrive at the bottom of a solids layer (as described in the previous section) and then migrate through the solids is certainly a different situation than those in situ generation studies. Still, the mechanisms governing the behavior of bubbles are much the same, so the previous work can provide significant insight into the bubble behavior in crusts.

The previous studies have identified two predominant mechanisms of bubble retention in typical waste configurations: particle-displacing bubbles retained in a continuum or fine particulate material due to the material yield strength, and interstitial liquid-displacing bubbles retained in a coarse particulate material because of capillary forces (Gauglitz et al. 1996; Johnson et al. 1997). A third configuration of bubbles, those directly attached to particles (armored bubbles, bubble attachment, and aggregates), is likely a significant configuration of bubbles arriving at the bottom of a crust, although it plays a minor role in the settled solids of a typical non-convective layer. Small bubbles stabilized by particles at the bottom of the crust might not coalesce or give up their gas through diffusion and could potentially form a foam or froth layer of very high gas fraction $(>0.5)$.

While gas retention in a foam layer at the bottom of the crust is an important consideration, particle-displacing bubbles retained in the waste because of the material strength are expected in the bulk of the SY-101 crust. The existence of particle-displacing bubbles rather than interstitial liquid-displacing bubbles in the bulk crust is based on scaling arguments developed in the previous work. This assumes that the weight of solids above bubbles or the buoyant load of waste below bubbles in the nearly neutrally buoyant crust is small. The previous studies developed and tested a dimensionless group that quantified the regimes for particle-displacing and interstitial-liquiddisplacing bubbles for both actual waste and simulants. This dimensionless group compared the weight forces of the settled solids above bubbles with the forces of surface tension and waste strength. In waste configurations with a thick layer of settled solids (and with coarse waste particles), interstitial-liquid-displacing bubbles were expected deep in the tank where the load is sufficient. In all other situations, particle-displacing bubbles were predicted. For bubbles in the nearly neutral crust, the small difference (about 18 inches) (see Figure 2.1) between the free liquid level and the top of the crust is a measure of the buoyancy. This represents a small gravitational force. Thus particle-displacing bubbles are expected in the crust.

Particle-displacing bubbles demonstrate a range of bubble shapes that depend on the surface tension of the gas-liquid interface, the bubble size, and the waste strength. Assuming negligible variation in surface tension in the waste materials, the shapes of bubbles of a given size are primarily a function of the waste strength. The strength of the material also affects the mechanism of gas release. Rassat et al. (1998) and Stewart et al. (1996b) give summaries of bubble release mechanisms and observations of the role of waste strength. In sufficiently weak wastes 
(e.g., $<10 \mathrm{~Pa}$ ), individual or small groups of round bubbles of sufficient size overcome the strength of the material to rise to the surface and release. At intermediate strength $(\sim 30-100 \mathrm{~Pa})$, distorted round bubbles establish comected paths to the waste surface only after attaining a relatively high gas fraction. A partial release of gas allows the surface to heal until the bubble path is reestablished through contimued gas generation and/or bubble migration. In even stronger materials (e.g., $\sim 1,000 \mathrm{~Pa}$ ), highly distorted and elongated dendritic bubbles connect to the surface at relatively lower gas fraction, and the material is strong enough to maintain a continual release pathway.

A very significant result of these bubble retention and release studies is that the gas retention in the waste materials never exceeds a maximum retention, and this maximum depends on the waste strength for particle-displacing bubbles. Rassat et al. (1998) summarize all of the laboratory results for actual wastes and simulants for maximum gas retention. For actual waste samples, the measured maximum retention was $40-50 \%$ void for saltcake and salt slurry wastes and $25-40 \%$ void for sludge-like wastes. These measurements fall within the expected range based on experiments with simulants.

For the bulk of SY-101 crust, the maximum gas retention should vary from 30 to $50 \%$, assuming 50 to $500 \mathrm{~Pa}$ as the expected range of strength for the crust. Based on the current estimate of about $35 \%$ void (average) in the crust (December 1998, waste level $\sim 425$ inches) and the possibility that the crust will increase to about $50 \%$ void, the waste level will rise an additional 20 inches (neglecting additional rise due to increased crust buoyancy). Thus the maximum attainable level in SY-101 should be about 445 inches, assuming other mechanisms of gas retention remain unchanged. This assumes, for example, that stable froths or foams that could result in significantly higher maximum gas fractions in the crust are not formed. (Previously, stable froths were observed during gas retention experiments on samples of AN-103 tank waste [Rassat et al. 1997].) The SY-101 level growth limit of $\sim 45$ inches also assumes that the crust continues to increase in void without having additional solids added to the crust. Because of the potential for mass addition to the crust and the (unanticipated) possibility of foam formation at the crust bottom, the $\sim 445$ inch growth limit must not be considered a conservative estimate.

Figure 4.1 shows three expected mechanisms of bulk gas (bubble) migration through the crust based on the understanding represented by the previous studies. These mechanisms broadly represent the expected behavior, and there will certainly be significant variation within each of these classes. Individual rising bubbles arrive at the bottom of the crust without coalescing with other bubbles or changing in any significant way. In percolation, an arriving gas bubble connects to an essentially connected percolation pathway. It is possible that this pathway opens and closes, but the essential idea is that the arriving gas pushes out the gas that is above it. In the third mechanism, the arriving bubbles migrate laterally to a local high spot, collect, and coalesce into a larger bubble that is then capable of rising as an individual bubble through the crust. While this rise of larger bubbles could shift randomly with time, it is quite possible that, once a local region becomes a high spot and has been weakened by previous gas releases, it will become the preferred location for gas release. A fourth mechanism of gas bubble migration, not depicted in Figure 4.1, is buoyancy of a bubbly mass (waste gobs, armored bubbles) through a crust opening or weak path. Upon reaching the surface, bubbles could pop, leaving behind fresh liquid and solids at the 


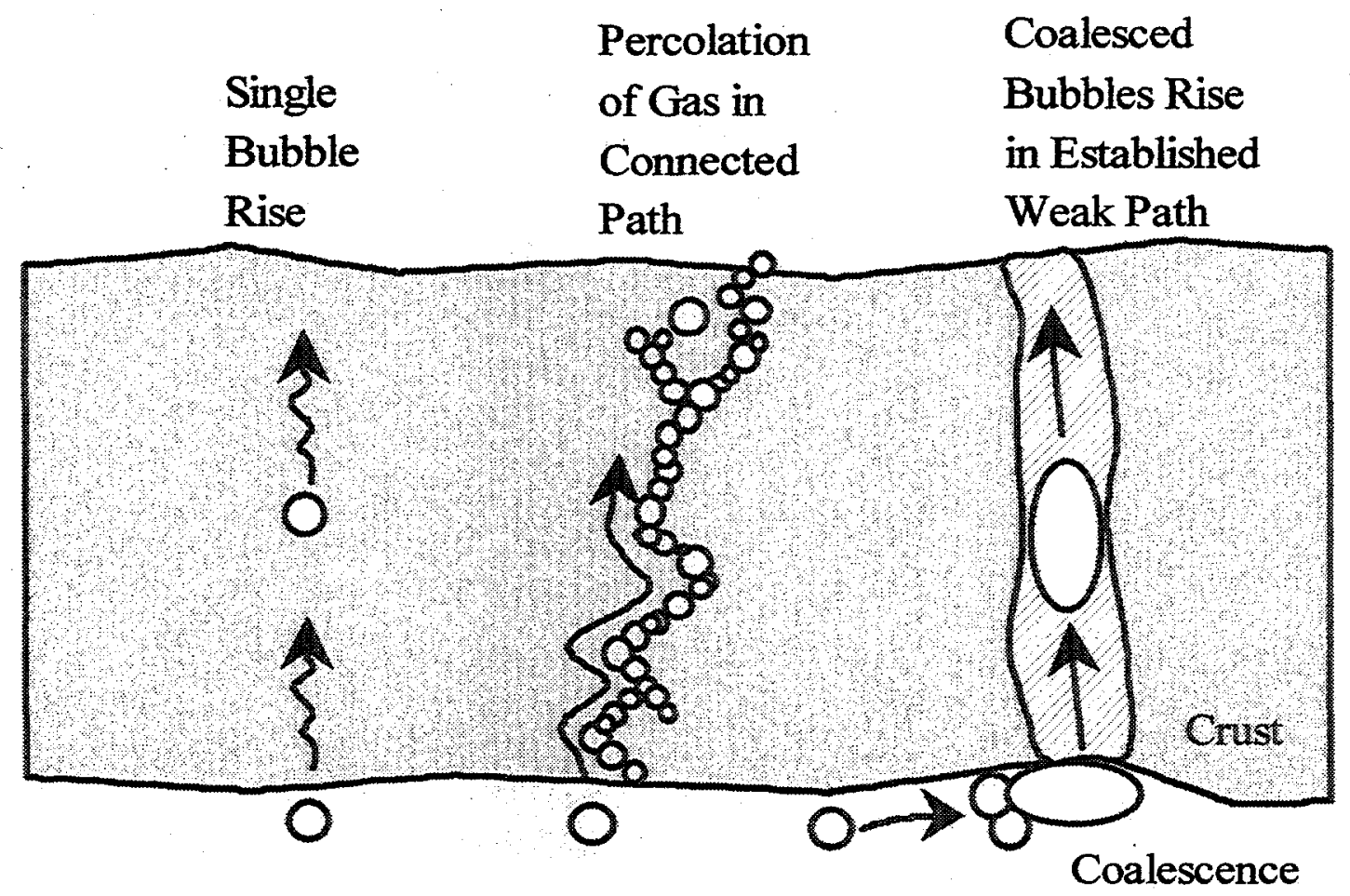

Figure 4.1. Mechanisms of Gas Migration Through a Floating Crust

crust surface in a fumarole. Entrained waste solids migrating with bubbles into existing crust openings could lead to crust vent closure.

Depending on the size of the arriving bubbles in relation to the strength of the crust material and configuration, various combinations of these four mechanisms will account for the release and slow accumulation of gas in the crust. In the following section, the roles of these mechanisms for various crust scenarios are discussed. 


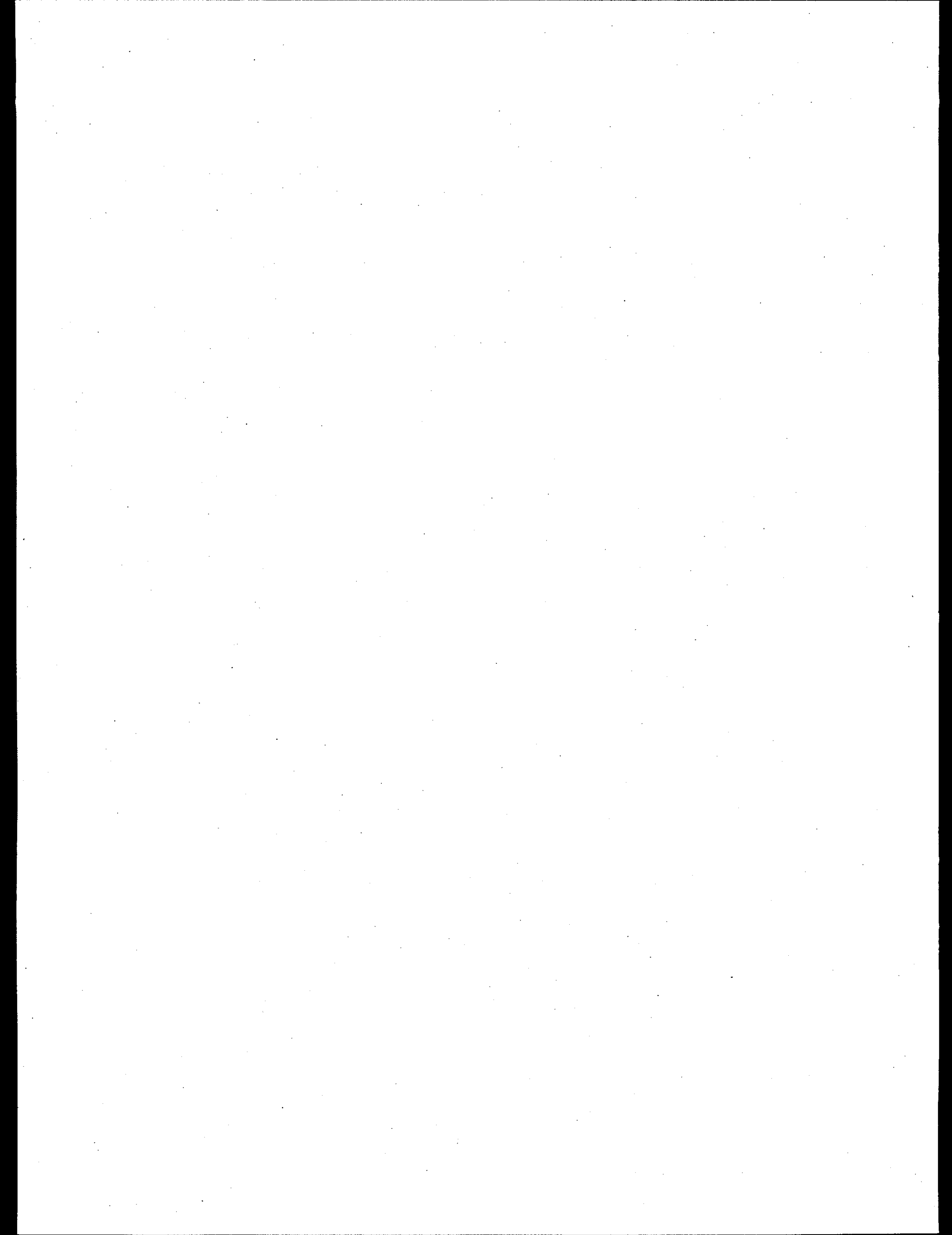




\subsection{Gas Retention and Release in Various Crust Configurations}

The physical configuration of the crust mass dictates the mechanisms of gas retention and release in crust and the magnitude of plausible gas release from the crust layer. Various crust configurations and the unique gas retention and release scenarios resulting from them are discussed in this section. The configurations are discussed according to the degree of vertical and lateral homogeneity in the crust properties.

Most, if not all, actual waste tank crusts are heterogeneous in some aspect. For example, visual evidence suggests that the SY-101 top crust surface, which is buoyed into the tank headspace, is relatively dry compared with the crust bottom, which is submerged in the convective layer. Additionally, photographs of the crust in Tank SY-101 indicate the surface level is highly nonuniform, possibly consisting of numerous floating waste bergs [see Figure 2.5 of Stewart et al. (1996b)]. Furthermore, recent VFI results indicate higher void fraction (0.4) near the lower crust interface than in the middle of the crust $(0.2-0.3)$, and a sudden increase in crane load during movement of the VFI upward within the crust layer suggests that the crust is weaker near the bottom than in the middle and upper parts (Stewart et al. 1998). Considering these factors and the expected mechanism of gas retention within the bulk of the crust as particle-displacing bubbles (see Section 4), a model of the likely SY-101 crust configuration is established. This is depicted schematically in Figure 5.1, where layer thicknesses are estimated from an analysis of recent tank data (see Figure 2.1 in Section 2.2). ${ }^{(2)}$ While the SY-101 crust is thought to resemble the heterogeneous mass shown in Figure 5.1, it is nonetheless instructive to consider gas retention and release in homogeneous crust configurations first. The mechanisms applicable in the homogeneous cases may also be pertinent in heterogeneous scenarios.

\subsection{Vertically Homogeneous Crust}

The primary gas retention and release mechanisms in a vertically homogeneous crust are identified in this section. A vertically homogeneous crust is an idealization in which the macroscopic crust properties, including retained void fraction, composition, strength, density, and surface (top and bottom) levels, are essentially uniform along a vertical vector through the crust mass. Actual tank crusts, including that in SY-101, are expected to have at least some degree of vertical inhomogeneity, however, the fundamental retention and release mechanisms identified for the vertically homogeneous crust also play a role in the real-world cases. These are discussed further in Section 5.2 under the topic of vertically heterogeneous crust. A crust that is vertically homogeneous may have lateral inhomogeneities in the form of channels, vents, or fissures. The laterally homogenous and heterogeneous crust cases are discussed in the following sections.

(a) Stewart CW. December 22, 1998. Data provided in a personal communication to SD Rassat, Pacific Northwest National Laboratory, Richland, Washington. 


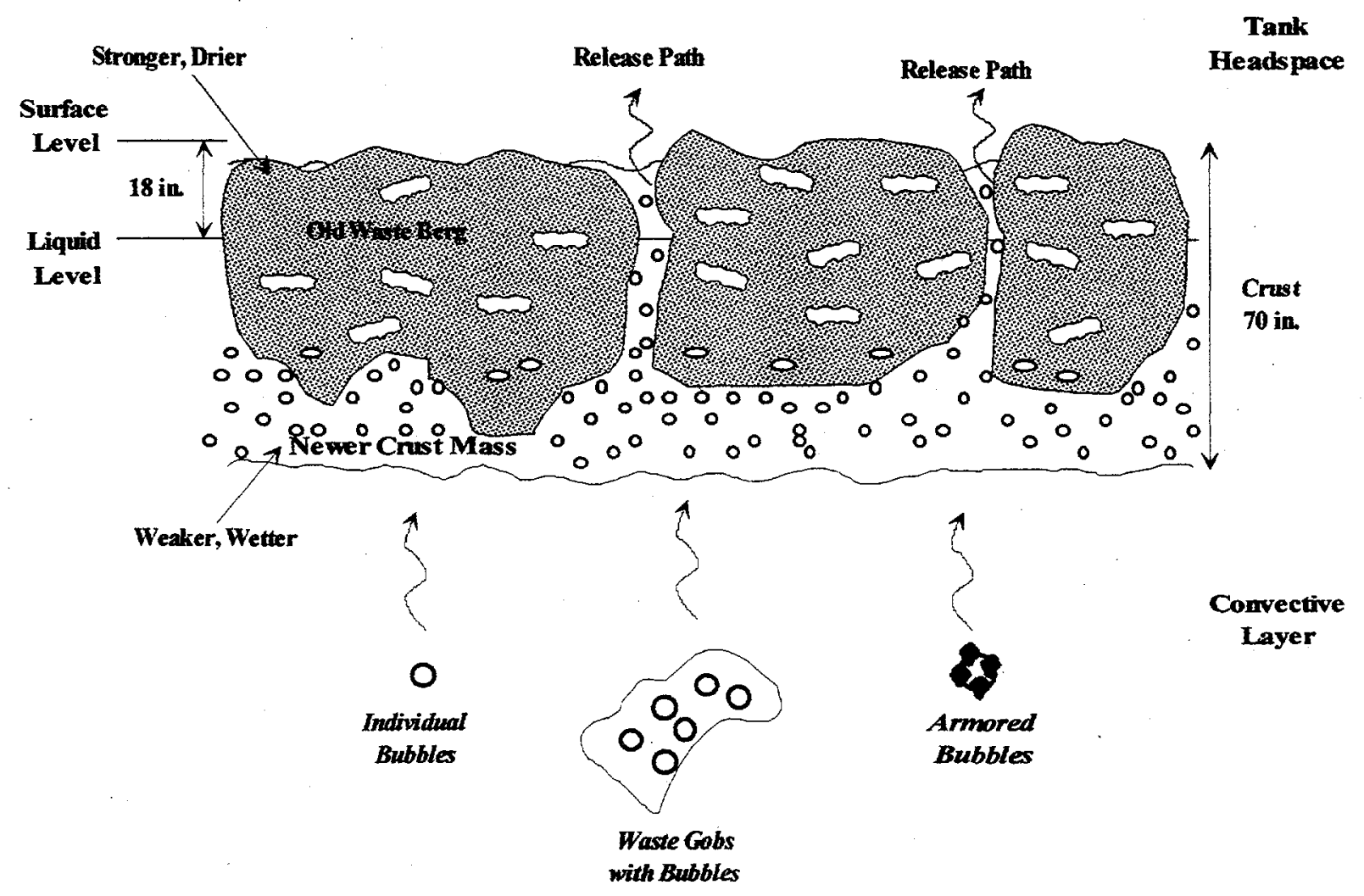

Figure 5.1. Schematic of Proposed SY-101 Crust Configuration

\subsubsection{Laterally Homogeneous}

The vertically and laterally homogeneous case represents complete homogeneity within the crust layer. In this scenario, there are no preferred paths resulting from lateral variations (e.g., vertical vents or fissures) in the crust. Therefore, all waste-generated gas reaching the tank headspace must pass through the crust mass.

- Individual Bubble Rise-As depicted in Figure 4.1 and discussed in Stewart et al. (1996b), individual round bubbles of sufficient size rise individually in relatively low-yield continuum materials. For example, the buoyant force of $0.1-\mathrm{cm}$ bubbles results in individual bubble rise in materials with less than $4 \mathrm{~Pa}$ yield strength, and it is predicted that a 1-cm bubble would rise freely in material less than $\sim 30 \mathrm{~Pa}$. Therefore, depending on the strength of the crust and the size of bubbles impacting and migrating through the crust, some gas may release to the headspace through direct bubble rise. The importance of this release mechanism under normal conditions is likely limited. First, any bubble smaller than $0.1 \mathrm{~cm}$ is probably retained by even a very weak crust, and many bubbles reaching the crust from the convective layer, particularly armored bubbles, could be smaller than this. (In time, these fine bubbles might coalesce on or within the crust to generate bubbles of sufficient size to undergo individual bubble rise.) Second, the crust is probably stronger than $\sim 30 \mathrm{~Pa}$, and the number of bubbles greater than 
the 1-cm diameter needed to rise individually is likely small. Further, as the strength of the material increases above $\sim 30 \mathrm{~Pa}$, bubbles begin to distort from their spherical shape, ultimately taking the form of highly distorted dendritic bubbles in strong materials. Percolation and Bubble Cascade releases are more plausible release mechanisms in homogeneous crusts.

- Percolation-Percolation is the mechanism by which connected paths of round bubbles (Figure 4.1), particle-displacing dendritic bubbles, and pore networks of interstitial liquiddisplacing bubbles in coarse particulate wastes are transported through a typical waste matrix (solid, liquid, and gas). (The concept of percolation is discussed further in Section 4.) The waste properties, including strength, particle size, and depth, affect the type of gas bubble retained, the maximum void fraction leading to a percolation release, and frequency at which releases occur. In the most extreme cases, releases from a $\sim 0.5$ maximum void fraction to $\sim 0.3$ void fraction have been observed in simulated and actual wastes of moderate strength $(\sim 50 \mathrm{~Pa})$ (Gauglitz et al. 1996; Rassat et al. 1998). In spite of this relatively large fractional gas release, the extent of any individual gas release through normal percolation in the SY-101 crust is expected to be small because the entire crust would not be involved in percolation simultaneously. Stewart et al. (1996b) discuss percolation releases in SST wastes, and their analysis indicates that the effective release column diameter is small (e.g., more than 1000 columns per tank).

- Bubble Cascade-In a bubble-laden waste mass, the rise of an individual bubble (see above) could initiate a cascade release of other round bubbles $(\sim 0.1-$ to $\sim 1-\mathrm{cm}$ diameter $)$. As the initial bubble rises, it captures and feeds off smaller bubbles in its path. The expanding bubble is able to penetrate stronger material directly, but its motion also yields the waste and results in the release of other, smaller individual bubbles nearby. Stewart et al. (1996b) modeled hypothetical gas releases in SST wastes resulting from bubble cascades. They assumed that the rising bubble influenced an area twice its diameter. Because of bubble expansion and growth due to coalescence, a conical volume of waste is disturbed in the cascade release. Therefore, the volume of gas released is highly dependent on the height of the waste as well as the initial void content. For a uniform 0.3 void fraction waste, they estimated bubble cascade gas release volumes of less than $5 \mathrm{~m}^{3}\left(180 \mathrm{ft}^{3}\right)$ in a 3-m-thick waste and less than $0.2 \mathrm{~m}^{3}\left(7 \mathrm{ft}^{3}\right)$ in a 1-m-thick waste. In December 1998, the SY-101 crust was estimated to be $\sim 1.8$-m thick and have an average void near 0.36 (see Section 2.2); bubble cascade gas releases from this crust are expected to be small, of the order $1 \mathrm{~m}^{3}\left(35 \mathrm{ft}^{3}\right)$. If the crust continues to retain gas to 0.5 void fraction, it will grow to $\sim 2.3-\mathrm{m}$ thick (neglecting addition of new crust mass). From this thicker crust, a bubble cascade release on the order of a few cubic meters or less is anticipated.

\subsubsection{Laterally Heterogeneous}

Lateral heterogeneities in an otherwise homogeneous crust include vertical vents and fissures that create open passages between the convective layer below the crust and the tank headspace above it. 
- Crust Openings-Openings in a vertically homogeneous crust provide a low-resistance route for migration of gas bubbles from two sources. When a vent or fissure is first formed in the crust, gas in the vicinity of the opening may percolate laterally through the crust. As a result of this release event, a depression would be expected in the crust surface adjacent to the opening. The lateral influence for gas migration to the opening is thought to be small, on the order of the size of a dendritic bubble intersecting the vent. Stewart et al. (1996b) argue that the lateral extent of these bubbles is probably three times the bubble height. Therefore, we expect the laterally affected area to be on the order of $0.1 \mathrm{~m}$ from the opening for typical large bubbles of order 1-cm height. As a result, gas releases in crust opening are expected to be small, but this will clearly depend on the size of vent or fissure created. Once formed, gas may continue to percolate laterally to the crust opening in a more continuous manner per typical percolation.

The vent or fissure also provides a release path for gas bubbles, bubbly waste gobs, and gassaturated liquid convected or buoyed directly to the crust opening as a result of mixer pump action. Bubbles that move laterally along the bottom of the crust or coalesce and grow to reach the opening are discussed in Section 5.2.2.

\subsection{Vertically Heterogeneous Crust}

Vertical heterogeneity of the crust gives rise to gas retention and release mechanisms that differ from the homogeneous case. Any vertical variation in crust properties including void fraction, composition, strength, density, and surface levels is considered a vertical heterogeneity. Such variations could result in barriers to the vertical migration of gas to the tank headspace. The expected vertical (and lateral) heterogeneity of SY-101 crust is depicted in Figure 5.1.

\subsubsection{Laterally Homogeneous}

In the vertically heterogeneous and laterally homogeneous scenario, the crust may be viewed as a layered material consisting of at least two distinct layers or as a continuously varying entity (infinite layers).

- Layered Crust and Bubble Pockets-As noted above, evidence and reason suggest that the SY-101 crust properties vary along any vertical segment. A most likely configuration is a relatively dry and strong crust surface consisting of older crust material covering a weaker, moist, and newer erust mass. The uppermost crust may be a crystallized porous network with non-retained gas that readily diffuses to the dome space (i.e., dried-out salt well) or with gas retained by liquid-filled pores in interstitial liquid-displacing bubbles. The main difference in these cases is the amount of gas actually retained in the crust. Another possibility is that the strong surface layer is composed of a continuum material in which gas is retained in particledisplacing dendritic bubbles (see Section 4). Whether gas is retained in the strong layer as interstitial liquid-displacing or particle-displacing dendritic bubbles, the maximum retention is expected to be near 0.3 to 0.35 void fraction. Once the maximum retention is reached, any excess gas reaching the layer must percolate through the waste in the typical way (Sections 4 
and 5.1.1) or find an alternative release route. It is conceivable that bubble pockets may form under the strong layer according to the following scenario. Individual bubbles of sufficient size will rise through a weak crust until they reach a layer of sufficient strength to impede their migration. Other bubbles migrating in that vicinity may coalesce when reaching the same barrier forming a pocket. The new, larger bubble (pocket) may continue to rise or may elongate horizontally, depending on the strength of the material above it. A very strong layer might be a collection point for a relatively large bubble pocket. The size of the bubble would be limited by the ability of the bubble to percolate through the upper layer and by the lateral distance to the nearest vertical vent (a lateral heterogeneity; see the discussion of Pooled Bubbles, below). Additional analysis is required to estimate the maximum size of a bubble pocket.

\subsubsection{Laterally Heterogeneous}

A crust that is heterogeneous both vertically and laterally gives rise to additional potential gas retention and release mechanisms, including lateral migration of individual bubbles, pooled bubble formation and release, and capsizing of waste bergs.

- Lateral Migration of Individual Bubbles to a Crust Opening-An individual bubble rising from the convective layer and contacting the lower crust surface is affected as follows: 1) if the bubble arrives with sufficient buoyant force to displace existing crust mass, it will be incorporated and may eventually migrate through the crust (see Section 5.1.1);2) the bubble may stick or be confined at the convective layer/crust interface (see Pooled Bubbles, below); or 3) the bubble could "slide" off an uneven, relatively hard surface (e.g., an old crust mass protruding through the crust bottom). The relative importance of these three bubble intermediate states is dictated by factors that include the bubble size and rise velocity, the strength of the lower crust layer, the dissimilarity of other crust and convective layer properties, the "sticking coefficient" of the crust, and the geometry of the lower crust surface. A bubble arriving at a convex or an upward-tilting surface is more likely to "roll" with some lateral component of motion and continue its buoyant rise. Provided the bubble does not stick to or penetrate the crust surface on its path, the laterally migrating bubble could eventually reach a vertical fissure or vent and complete its buoyant rise, releasing directly to the tank headspace. This mechanism of gas release leads to small, but perhaps nearly continuous gas release volumes. It should be noted that hydrostatic pressure at the convective layer/crust interface would tend to smooth any weak crust material protruding downward from the crust bottom and thereby reduce extremes in convex and concave crust surfaces.

- Pooled Bubbles-Individual bubbles that stick to or are confined at the convective layer/crust interface may coalesce with adjacent individual bubbles to form pooled bubbles. Lower crust surface geometry is an important factor controlling the size of pooled bubbles. In the discussion of Lateral Migration of Individual Bubbles (above), a bubble impacting a convex surface is more likely to "roll" and continue its buoyant rise. On the other hand, a concave (down) surface acts to funnel the bubbles to central location where they coalesce in a pool. The pitch of the concave surface will affect the relative vertical and lateral extent (aspect ratio) of the lens-shaped bubbles. As the crust bottom surface becomes flatter, these pooled 
bubbles preferentially spread laterally through the paths of least resistance, and this pancake bubble may eventually reach a path (vent or fissure) connected to the tank dome space. Steeper-pitched concave surfaces would result in more rounded bubbles, which provide relatively high bubble pressure (per unit bubble volume) on the crust surface immediately above the bubbles. These more spherical bubbles are more likely to overcome the strength of the material and push vertically through the crust. This may result in fumaroles in the upper crust surface that identify the vent location (see Figure 2.5, Stewart et al. 1996b). Gas releases from pooled bubbles should be larger but less frequent than individual bubble releases. Further evaluation is needed to assess the potential size of pooled bubbles and releases therefrom.

- Capsizing Waste Bergs - The SY-101 crust probably consists of a series of individual floating "original" waste bergs separated or only loosely adhered at vertical fissures by much weaker "fresh" crust material (Figure 5.1). Recent VFI data indicate a higher void fraction near the base of the crust than in the middle (Stewart et al. 1998). This may correspond to an unstable configuration with a more dense, low void crust on top of a relatively buoyant low-density crust at the convective layer interface. Individual waste bergs in this unstable density configuration have the potential to capsize. A waste berg that has a broader base than the thickness (height) should be stable to capsizing. Waste bergs that are narrower than they are thick are less stable in an open liquid field but may be relatively stable in a confined field of waste bergs, depending on the strength of the crust and the ability of the surrounding crust to support the load of the leaning berg. Perhaps the most unstable berg size, the one most susceptible to inversion, is that with a base approximately equal in dimension to its height, because its lateral extent provides space for its vertical extent when it inverts. Upon inversion, a relatively strong dry crystalline crust top would likely undergo softening and partial dissolution in the convective layer. This softening, and the shear forces resulting from the inversion process, would tend to release gas in the vicinity of the berg. To date, comparative video scans of the SY-101 crust surface indicate that waste bergs have not capsized.

Figure 5.2 shows the estimated gas release volumes resulting from capsizing of a single waste berg cube (width equal to thickness) of varying initial void fraction. (The SY-101 crust is assumed to be $\sim 70$-inches $(1.8-\mathrm{m})$ thick at a gas fraction $\sim 0.35$ according to the most recent property estimates discussed in in Section 2.2.) In the simple berg capsizing model, bubble expansion and contraction over the relatively short crust inversion path was neglected. The final void state of the capsized berg was varied from 0.0 to 0.3; this is also shown in Figure 5.2 as the series of dashed lines representing gas release volumes. It is unclear what the final gas content of the inverted berg would be. Minimally, a release to a final bulk average void of 0.3 is predicted based on relatively sudden and large releases of particle displacing bubbles in moderate strength $(\sim 50 \mathrm{~Pa})$ bentonite clay simulants (Gauglitz et al. 1996) and actual waste samples (e.g., S-102) (Rassat et al. 1998), from maximum void fractions of $0.4-0.5$ to final void fractions near 0.3 . As shown in Figure 5.2, capsizing of a single berg initially at 0.5 void fraction would result in $3.5-\mathrm{m}^{3}\left(120-\mathrm{ft}^{3}\right)$ gas release to a final state of 0.3 void fraction. The complete release of gas ( 0.0 final void fraction) from the same berg is a $6.2-\mathrm{m}^{3}\left(220-\mathrm{ft}^{3}\right)$ release, whereas the complete release from a crust berg at the current 0.35 gas fraction is 


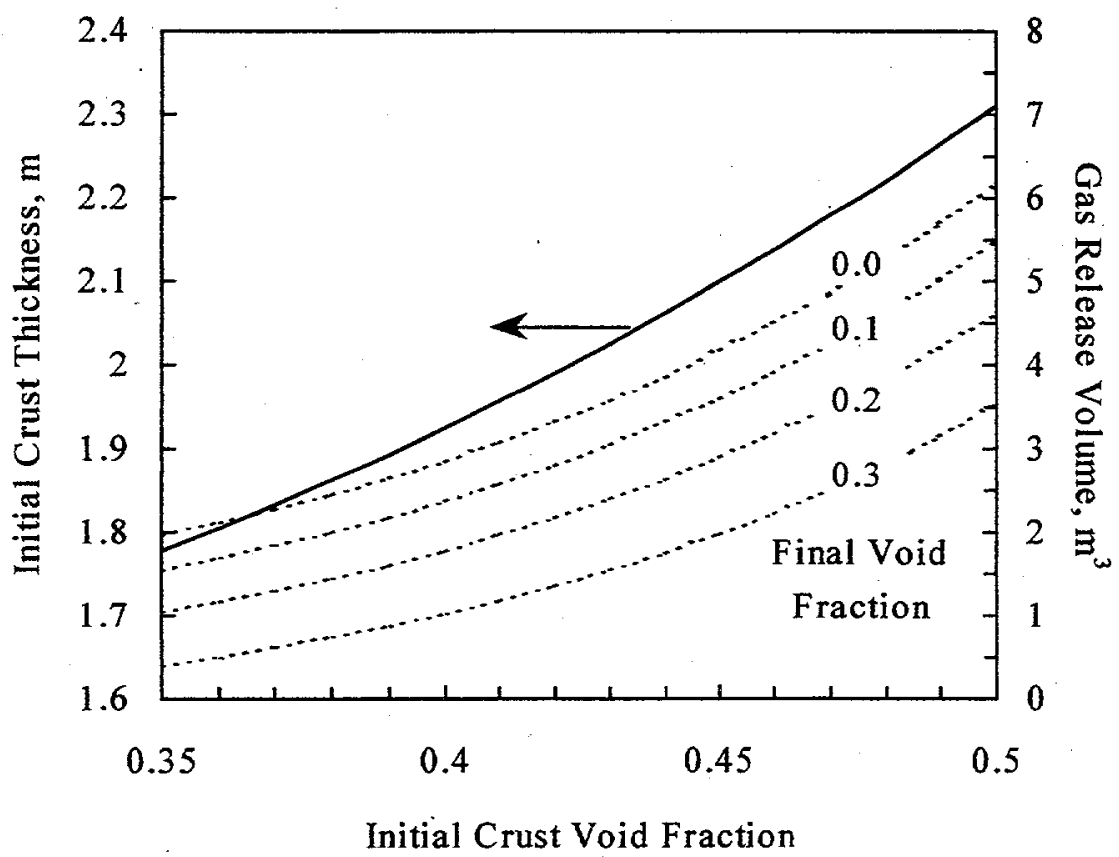

Figure 5.2. Variation in Crust Thickness (solid line) with Crust Void Fraction and the Effect on Gas Release Volumes (dashed lines) for Capsizing Single Waste Berg Cubes (width equal to thickness). The retained void fraction after gas release is varied from 0 to 0.3 .

only one-third as big $\left(2.0 \mathrm{~m}^{3}\right)$. The predicted increase in crust thickness resulting from increased retained crust gas fraction (abscissa) is also shown in Figure 5.2. 


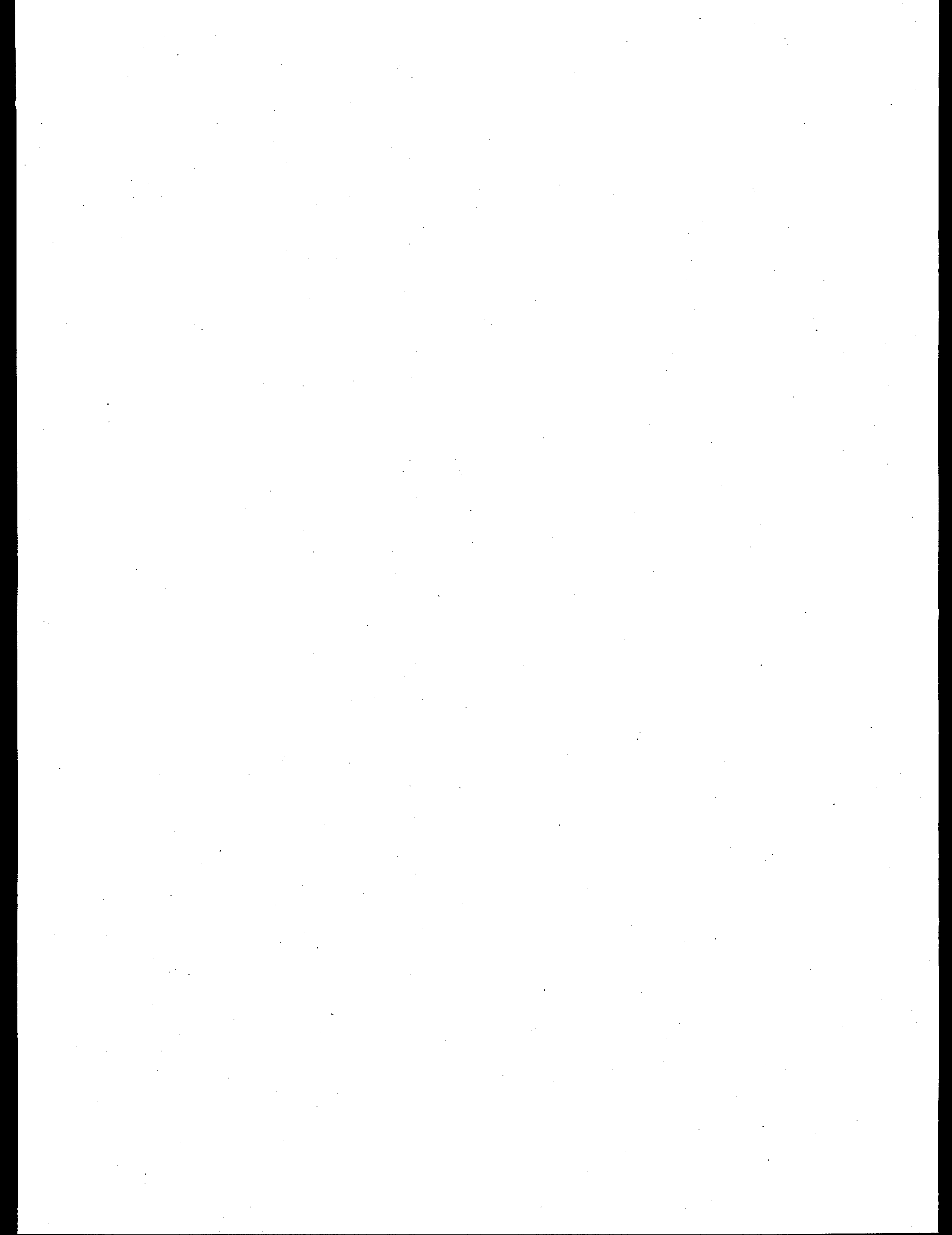




\subsection{Mechanisms of Sudden Release}

In addition to the "natural" gas release mechanisms noted for the various crust configurations in Section 5, other external forces may lead to sudden gas releases from the SY-101 crust. These include crust gas releases from wetting the top crust, crust disruption in waste transfer, intrusion through the crust, and earthquakes. Both the magnitude and rate of gas release may differ in these release scenarios, with earthquakes most likely to produce the largest sudden release.

- Crust Wetting - Wetting of the crust surface by widespread but minimal volume water addition (e.g., fine spray) or humidification is likely to release gas from the crust and will ultimately lead to modification of the retention and release properties of the crust. Assuming the crust top is relatively dry crystalline salt, wetting the surface will promote dissolution of the crust surface. During dissolution, trapped gases within the crystalline matrix and in pores adjacent to it will be released to the tank beadspace. It is clear that the crust gas release rate could be controlled by the rate of wetting and the resulting rate of crust dissolution (provided the dissolution physics are well understood). However, partial dissolution of the crust may lead to a less stable crust configuration. First, if the initial crust surface is sufficiently dry and porous that gas freely diffuses to the tank headspace (non-retained gas), then addition of small amounts of water could plug pores with the resulting salt solution. This would produce a more effective barrier to gas migrating from the already-moist lower crust. Additionally, partial dissolution of the upper crust will modify the density profile of the crust, producing a relatively dense gas-free layer on top if water additions are small. Although the new dense layer should have a lower center of gravity, the net effect may further destabilize the crust and lead to waste berg capsizing (see Section 5.2.2 and Earthquake below). Bulk water additions in localized areas of the crust (e.g., water lancing) are treated separately below under the topic of Intrusion.

- Crust Disruption (waste transfer)-Retrieval of convective waste from below the crust surface may disrupt the crust. In one extreme, a free-floating crust would follow the liquid level directly as convective waste is removed, the crust would not be disrupted, and the gas retention and release scenarios described in Section 5 would prevail. At the other end of the spectrum, the crust would be partly or entirely suspended above the receding convective layer because of the strength of the crust and interaction at the tank wall or other fixed tank equipment submerged in the waste. In SY-101, complete suspension is improbable because of the mass and the weakness of the crust, so this scenario will not be considered further. More reasonably, crust in the center of the tank will follow the liquid level, while crust at the tank periphery is hung up. At a minimum, this will result in modest gas releases from the shear zone between the hung-up and the floating crust. Gas would be released from any pooled gas adjacent to freshly formed vents and fissures (Section 5.2.2), and gas would migrate laterally over a relatively short distance from the newly created surfaces (Section 5.1.2). Most importantly, the free-floating crust in the middle of the tank may be more likely to capsize. Without the support of the tank wall or an outer confining crust layer, a domino waste berg release is conceivable. Crust waste bergs at the periphery of the new floating layer roll outward, pushed by leaning bergs in the center of the tank. This scenario likely would 
produce gas releases smaller than those for earthquake disruption (see below). The bergs capsized in waste retrieval may ultimately retain more gas than in the earthquake scenario because the shearing forces in an earthquake may be considerably more substantial.

Additionally, the entire crust surface may not participate in the domino game because some of the individual bergs could be broad-based and stable (Section 5.2.2).

- Intrusion-Localized, small-area intrusions through the crust are not expected to result in large gas releases. Stewart et al. (1996b) evaluated available data for gas releases from Hanford DSTs resulting from core sampling, water lancing in support of VFI measurements, and ball rheometer measurement runs. They found the releases were relatively small; the largest was less than $20 \mathrm{~m}^{3}\left(700 \mathrm{ft}^{3}\right)$. Furthermore, recent intrusions through the SY-101 crust for VFI testing have not resulted in significant gas releases. In one case, however, video cameras indicated that a bubbly mass flowed through the vent created by water lancing. The release was not particularly energetic or large. In general, the largest and most sudden release from local intrusion through the crust may result from tapping directly into a pooled bubble (Section 5.2.2). Minimally, a gas release equivalent to the volume of gas retained in the disturbed crust is expected. Small additional amounts of gas will likely release through lateral migration (Section 5.1.2).

- Earthquake-Earthquakes might result in large, rapid gas releases from the SY-101 crust. Stewart et al. (1996b) and Reid and Deibler (1997) showed that seismic events have the potential to yield the entire tank contents, depending on the energy imparted by the earthquake and the strength and other rheological properties of the waste. Yielding of the SY-101 crust in an earthquake could result in a bubble cascade release (Section 5.1.1) directly affecting all parts of the crust simultaneously. Additionally, the motion imparted by the seismic event might lead to crust fracturing and capsizing of waste bergs. Figure 6.1 shows estimated gas release volumes for SY-101 crust of varying initial void fraction (correlated to crust thickness). The assumptions in the simple release model are similar to those used to prepare Figure 5.2 and discussed in Section 5.2.2, Capsizing Waste Bergs. The key difference is that the entire crust surface, not just an individual waste berg, is assumed to participate in the catastrophic release scenario depicted in Figure 6.1. Because of the energy imparted by even a modest earthquake, significant deformation of the crust and gas release is expected. A minimal seismic event resulting in only partial gas release from the entire crust, say from the current $\sim 0.35$ void fraction (Section 2.2 ) to a final of 0.25 , corresponds to a significantly large $97-\mathrm{m}^{3}\left(3400-\mathrm{ft}^{3}\right)$ release. This hypothetical release is larger than the last major gas release $\left(\sim 2200 \mathrm{ft}^{3}\right)$ from SY-101 on August 27, 1993, which occurred at the end of Phase A pump tests (Allemann et al. 1994). 


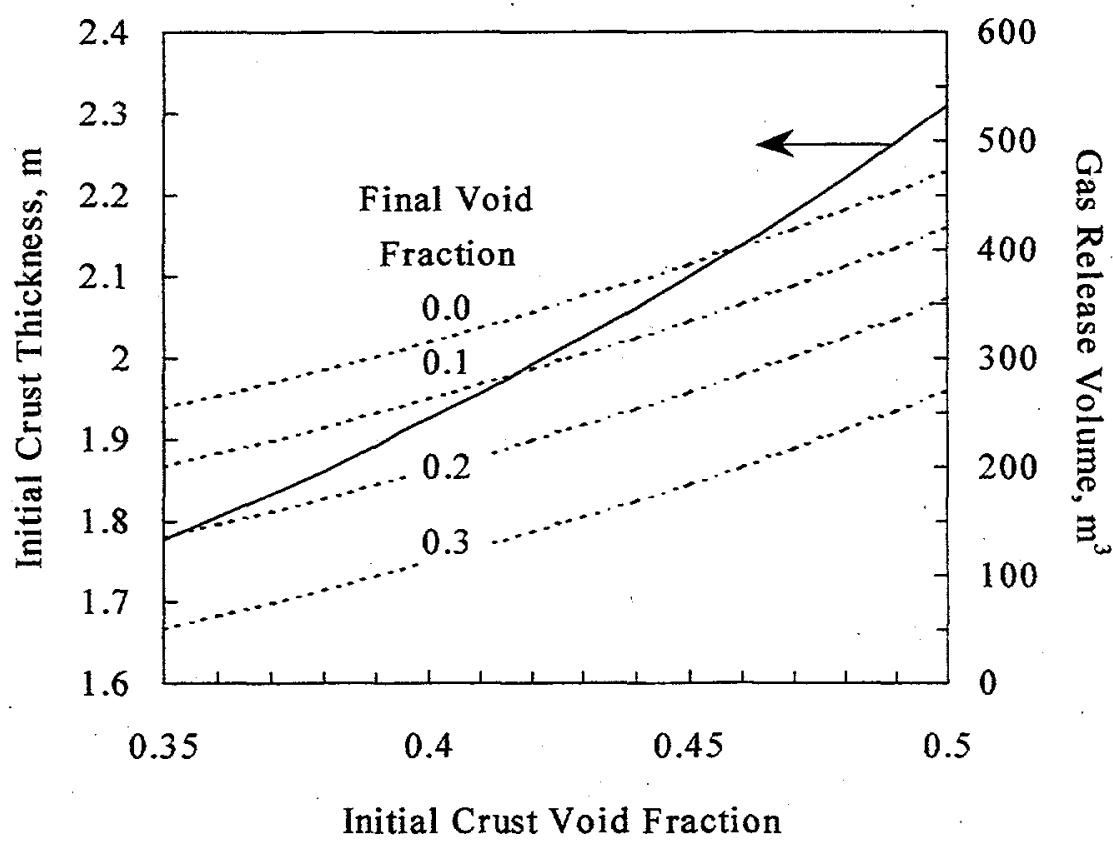

Figure 6.1. Variation in Crust Thickness (solid line) with Crust Void Fraction and the Effect on Gas Release Volumes (dashed lines) for Global Release Throughout the Crust Layer. The retained void fraction after gas release varies from 0 to 0.3 . 


\subsection{Experiments}

A series of laboratory experiments was performed to observe gas retention and release in floating crusts. Three different crust simulants were used: polymethyl-methacrylate (PMMA) particles, carboxyl polymethylene (Carbopol), and bentonite clay. Water was added to each crust simulant to form a crust of a desired strength. For the bentonite clay, hydrogen peroxide was used to generate gas bubbles and make the simulant buoyant. For the carbopol, an air sparger was used to promote the generation and entrapment of gas bubbles. Difficulties were encountered when attempting to float these crust simulants on water due to the lack of sufficient buoyancy. However, both these simulants have potential and should be explored further. The Carbopol simulant is particularly attractive because it is clear, allowing easy observation of retained and released bubbles.

Successful experiments were performed using wetted PMMA particles to simulate the floating crust. Water, PMMA particles, and a small amount of a surfactant (Joy dishwashing soap) were mixed in a KitchenAid blender. A wire whisk was attached to the blender to promote the generation and entrapment of gas bubbles, allowing the simulant to become buoyant and float on top of water. A 2- to 3-inch layer of the PMMA crust was placed on top of approximately 6 inches of tap water in an 8-inch diameter glass vessel. Gas bubbles were introduced beneath the crust with an air sparger. The rate of bubble generation was controlled at between 10 and $20 \mathrm{sccm}$ (standard $\mathrm{cm}^{3}[\mathrm{~mL}]$ per minute) using a Brooks $5850 \mathrm{E}$ mass flow controller. Two video cameras were used to observe and record the bubbles (about $0.5 \mathrm{~cm}$ diameter) as they were generated and released into the crust. A Sekai Electronics camera, model ISC-800A, was used to observe the bubbles as they entered the bottom of the crust. A Leica camera attached to a Wild stereo microscope was used to observe the release of the bubbles through the top of the crust.

During the experiment, thousands of single bubbles were observed to coalesce on the bottom of the crust layer into a single large bubble, which eventually breached the crust after approximately 15 minutes of air sparging. Once the release pathway was formed, much smaller bubbles were capable of releasing though the pathway. These subsequent releases occurred approximately every 2 to 3 minutes. Figure 7.1 shows how the large bubble formed by coalescence grew during the first 15-minute release event and the location of the release. Subsequent smaller gas releases occurred in the same location. 


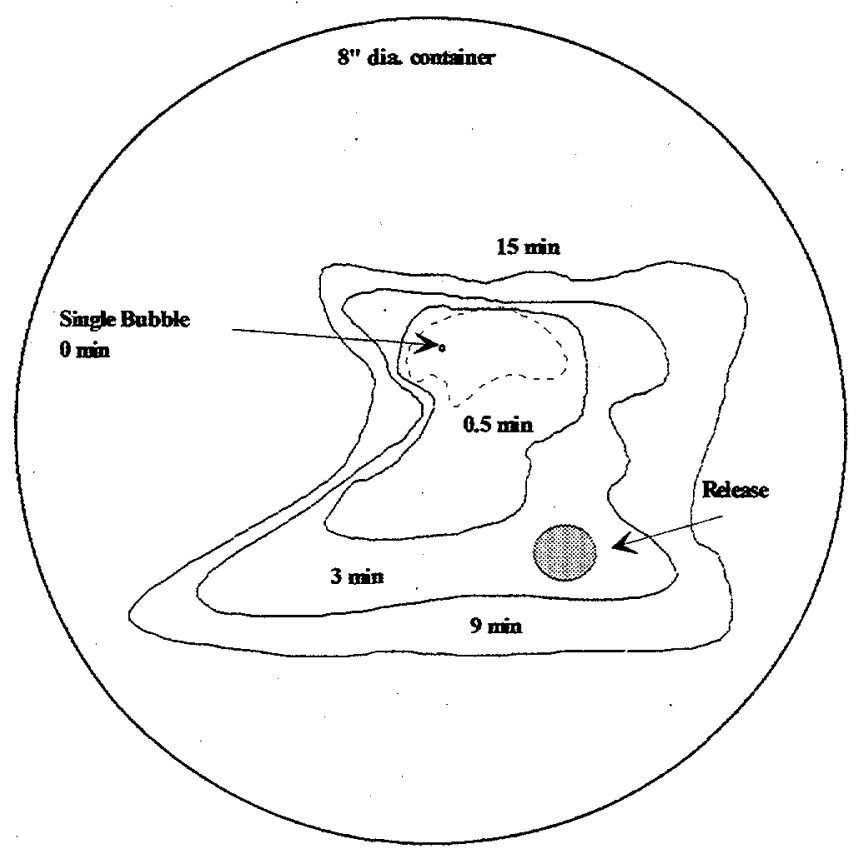

Figure 7.1. Bubble Coalescence and Release During PMMA Simulated Crust Experiment 


\subsection{Conclusions and Recommendations}

The results presented in this report are preliminary conclusions and predictions of expected behavior. Further studies are needed to confirm and test the validity of these results. Based on the results at this writing, these are our conclusions:

- Based on previous studies and theory, the gas in the crust should be in the form of particledisplacing bubbles that are retained by the strength of the crust material.

- Perhaps the most significant prediction based on the existing bubble retention and release models is that the bulk of the crust will reach a maximum gas fraction $(\sim 50 \%)$ and will stop retaining additional gas, limiting the crust level rise. This assumes that the crust is typical of most waste materials observed in our laboratory to date, in which the maximum retention of particle-displacing bubbles is dictated primarily by the waste strength. It further assumes that stable froths or foams are not formed and that crust mass is not being added.

- However, the most recent analysis (December 1998) indicates that increases in crust thickness are partly attributed to mass additions to the crust. In addition, the formation of stabilized foam or froth at the bottom of the crust cannot be ruled out. Therefore, conservatively speaking, a limit cannot be placed on the waste level without further consideration of these factors.

- A crust physical configuration (schematic model) is proposed. The model crust is a heterogeneous mass consisting of both "old" and "new" material in which the macroscopic physical properties vary in both vertical and lateral directions. Gas retention and release from simplified hypothetical crusts having varying degrees of heterogeneity are considered. In addition to the release of gas through the rise of individual bubbles and the percolation of gas through pathways of connected bubbles, preliminary experimental results suggest that the formation and release of pooled bubbles at the bottom of the crust may be an important mechanism.

- External forces that may lead to sudden gas releases from the SY-101 crust are postulated. These scenarios include crust gas releases resulting from wetting of the crust top, crust disruption in waste transfer, intrusion through the crust, and earthquakes. Both the magnitude and rate of gas release are expected to differ in these release scenarios.

- Sudden gas releases from most crust configurations and release scenarios are expected to be relatively small, perhaps on the order of $10 \mathrm{~m}^{3}\left(350 \mathrm{ft}^{3}\right)$ or less. However, considerably larger releases are likely in the case of earthquake disruption and are conceivable for crust disruption resulting from waste transfer. 


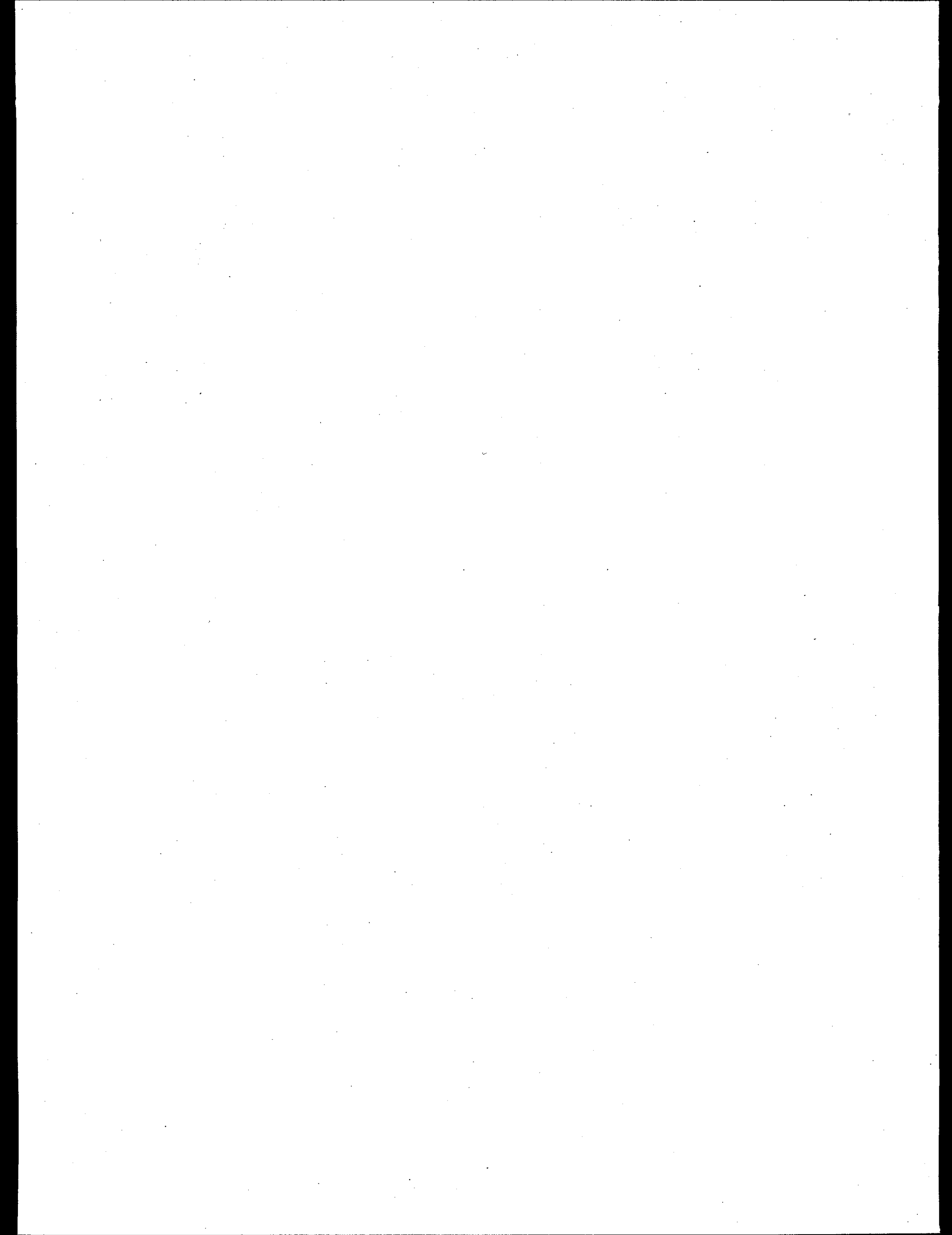




\subsection{References}

Allemann RT, TM Burke, DA Reynolds, and DE Simpson. 1993. Assessment of Gas Accumulation and Retention - Tank 241-SY-101. WHC-EP-0576 Rev. 0, Westinghouse Hanford Company, Richland, Washington.

Allemann RT, ZI Antoniak, WD Chvala, LE Efferding, JG Fadeff, JR Friley, WB Gregory, JD Hudson, JJ Irwin, NW Kirch, TE Michener, FE Panisko, CW Stewart, and BM Wise. 1994. Mitigation of Tank 241-SY-101 by Pump Mixing: Results of Testing Phases A and B. PNL-9423, Pacific Northwest National Laboratory, Richland, Washington.

Baldwin JH. 1995. Tank Characterization Report for Double-Shell Tank 241-AW-101. WHCSD-WM-ER-470 Rev. 0, Westinghouse Hanford Company, Richland, Washington.

Bell K. 1994. 136 Day Deliverable Report, Double Shell Tank 241-SY-103. WHC-SD-WMDP-073 Rev. 0, Westinghouse Hanford Company, Richland, Washington.

Benar CJ. 1996. Tank 241-AW-101, Cores 132 and 139 Analytical Results for the Final Report. WHC-SD-WM-DP-192 Rev. 0, Rust Federal Services of Hanford, Inc., Richland, Washington.

Bredt PR and SM Tingey. 1996. The Effect of Dilution on the Gas Retention Behavior of Tank 241-SY-103 Waste. PNL-10893, Pacific Northwest National Laboratory, Richland, Washington.

Bredt PR, SM Tingey, and EH Shade. 1995. The Effect of Dilution on the Gas-Retention Behavior of Tank 241-SY-101 Waste. PNL-10781, Pacific Northwest Laboratory, Richland, Washington.

Brewster ME, NB Gallagher, JD Hudson, and CW Stewart. 1995. The Behavior, Quantity, and Location of Undissolved Gas in Tank 241-SY-101. PNL-10681, Pacific Northwest National Laboratory, Richland, Washington.

Gauglitz PA, LA Mahoney, DP Mendoza, and MC Miller. 1994. Mechanisms of Gas Bubble Retention. PNL-10120, Pacific Northwest Laboratory, Richland, Washington.

Gauglitz PA, SD Rassat, MR Powell, RR Shah, and LA Mahoney. 1995. Gas Bubble Retention and its Effect on Waste Properties: Retention Mechanisms, Viscosity, and Tensile and Shear Strength. PNL-10740, Pacific Northwest Laboratory, Richland, Washington.

Gauglitz PA, SD Rassat, PR Bredt, JH Konynenbelt, SM Tingey, and DP Mendoza. 1996. Mechanisms of Gas Bubble Retention and Release: Results for Hanford Waste Tanks 241-S-102 and 241-SY-103 and Single-Shell Tank Simulants. PNNL-11298, Pacific Northwest National Laboratory, Richland, Washington. 
Gauglitz PA and JT Aikin. 1997. Waste Behavior During Horizontal Extrusion: Effect of Waste Strength for Bentonite and Kaolin/Ludox Simulants and Strength Estimates for Wastes from Hanford Waste Tanks 241-SY-103, AW-101, AN-103, and S-102. PNNL-11706, Pacific Northwest National Laboratory, Richland, Washington.

Herting DL. 1992a. Laboratory Characterization of Samples Taken in May 1991 from Hanford Waste Tank 241-SY-101. WHC-SD-WM-DTR-024, Westinghouse Hanford Company, Richland, Washington.

Herting DL. 1992b. Laboratory Characterization of Samples Taken in December 1991 (Window E) from Hanford Waste Tank 241-101-SY. WHC-SD-WM-DTR-026, Westinghouse Hanford Company, Richland, Washington.

Johnson GD, WB Barton, JW Brothers, SA Bryan, PA Gauglitz, RC Hill, LR Pederson, CW Stewart, and LM Stock. 1997. Flammable Gas Project Topical Report. PNNL-11500, Richland, Washington (also published as HNF-SP-1193, Rev. 2., Hanford, Washington).

Levich VG. 1962. Physiochemical Hydrodynamics. Prentice-Hall, New Jersey.

Meyer PA, ME Brewster, SA Bryan, G Chen, LR Pederson, CW Stewart, and G Terrones. 1997. Gas Retention and Release Behavior in Hanford Double-Shell Waste Tanks. PNNL-11536 Rev. 1, Pacific Northwest National Laboratory, Richland, Washington.

Rassat SD and PA Gauglitz. 1995. Bubble Retention in Synthetic Sludge: Testing of Alternative Gas Retention Apparatus. PNL-10661, Pacific Northwest Laboratory, Richland, Washington.

Rassat SD, PA Gauglitz, PR Bredt, LA Mahoney, SV Forbes, and SM Tingey. 1997. Mechanisms of Gas Retention and Release: Experimental Results for Hanford Waste Tanks 241$A W-101$ and 241-AN-103. PNNL-11642, Pacific Northwest National Laboratory, Richland, Washington.

Rassat SD, SM Caley, PR Bredt, PA Gauglitz, DE Rinehart, and SV Forbes. 1998. Mechanisms of Gas Retention and Release: Experimental Results for Hanford Single-Shell Waste Tanks 241-A-101, 241-S-106, and 241-U-103. PNNL-11981, Pacific Northwest National Laboratory, Richland, Washington.

Reid HC and JE Deibler. 1997. Seismic Event-Induced Waste Responses and Gas Mobilization Predictions for Typical Hanford Waste Tank Configurations. PNNL-11668, Pacific Northwest National Laboratory, Richland, Washington.

Shekarriz A, DR Rector, LA Mahoney, MA Chieda, JM Bates, RE Bauer, NS Cannon, BE Hey, CG Linschooten, FJ Reitz, and ER Siciliano. 1997. Composition and Quantities of Retained Gas Measured in Hanford Waste Tanks 241-AW-101, A-101, AN-105, AN-104, and AN-103. PNNL-1 1450 Rev. 1, Pacific Northwest National Laboratory, Richland, Washington. 
Stewart, CW, JD Hudson, JR Friley, FE Panisko, ZI Antoniak, JJ Irwin, JG Fadeff, LF Efferding, TE Michener, NW Kirch, and DA Reynolds. 1994. Mitigation of Tank 241-SY-101 by Pump Mixing: Results of Full-Scale Testing. PNL-9959, Pacific Northwest National Laboratory, Richland, Washington.

Stewart CW, JM Alzheimer, ME Brewster, G Chen, RE Mendoza, HC Reid, CL Shepard, and G Terrones. 1996a. In Situ Rheology and Gas Volume in Hanford Double-Shell Waste Tanks. PNNL-11296, Pacific Northwest National Laboratory, Richland, Washington.

Stewart CW, ME Brewster, PA Gauglitz, LA Mahoney, PA Meyer, KP Recknagle, and HC Reid. 1996b. Gas Retention and Release Behavior in Hanford Single-Shell Waste Tanks. PNNL11391, Pacific Northwest National Laboratory, Richland, Washington.

Stewart CW, JM Alzheimer, G Chen, and PA Meyer. 1998. In Situ Void Fraction and Gas Volume in Hanford Tank 241-SY-101 as Measured with the Void Fraction Instrument. PNNL12033, Pacific Northwest National Laboratory, Richland, Washington.

Wilkins NE, JG Field, LW Shelton, and TL Welsch. 1997. Tank Characterization Report for Double-Shell Tank 241-AN-103. HNF-SD-WM-ER-702 Rev. 0, Lockheed Martin Hanford Corporation, Richland, Washington. 


\title{
Appendix A
}

Summary of Crust Workshop on May 28, 1997

\author{
GD Johnson
}




\section{Appendix A}

\section{Summary of Crust Workshop, May 28,1997}

As part of the meeting with the Chemical Reactions Sub-Panel on May 28, 1997, a session was held to explore various aspects of "crusts" in Hanford waste tanks. Jerry Johnson gave the introduction. He noted that the term "crust" is being applied to floating masses of various thicknesses. Observations for double-shell tanks (DSTs) (based on MIT validation probe data) have shown that, for six DSTs, the crust layers ranged from 20 to $100 \mathrm{~cm}$ thick. Tank A-101 (a single-shell tank [SST]) has perhaps the largest crust layer, which is estimated to be $425 \mathrm{~cm}$ thick. The topics for discussion in this session were the nature of crust material, processes for crust formation, storage of gas, steady-state gas release, spontaneous gas release, induced gas release, ignition of gas and flame propagation, and potential tests or measurements.

\section{Nature of the Crusts}

Kevin Bell gave a presentation on the data obtained from core sampling events for six DSTs and one SST. He concluded that the crust composition, in general, is similar to that of the nonconvective layer in the DSTs. There were also indications that the liquids had a similar composition except that the crust was always higher in phosphate and sulfate and lower in nitrate than the liquids. The moisture content in the crusts was somewhat similar to the other layers in the tanks.

\section{Discussion}

The main points raised during the discussion session:

- The density values for crust layers are not representative of actual tank conditions.

- To understand the crusts, it is necessary to go beyond the simple listing of major analytes.

- Should look at morphology of crystals as well as compositions.

$>$ Consider using x-ray analysis, scanning electron microscopy, etc.

Need better data for TOC and which organics are present

Could look for uptake of carbon dioxide from TIC

Need consistent approach for reporting TOC values

Knowledge of the radionuclides in the crust would

- aid in the determination of gas production as well as "source term" data for consequence analyses. 
Chuck Stewart gave a video presentation of the crust in several tanks. The video also showed several waste intrusive events. It appeared that there were no major releases during these events. Chuck also noted that the gas monitoring data showed some tanks had minor releases during these activities.

\section{Processes for Crust Formation}

Phil Gauglitz presented some ideas on how a crust could form. He covered three mechanisms: 1) the rise of a bubbly waste glob (starting as neutrally buoyant), 2) the rise of bubble-particle agglomerates, or single bubble-particle pairs, and 3) the rise of individual bubbles. In all cases, the rising entity would then be held up at the top of the waste. Growth of the crust could then be related to waste yield strength and capillary forces. He also discussed the use of a "Bond" number to determine whether the crust would have connected bubbles or particle displacing bubbles.

\section{Discussion}

There was a rather extended discussion on the various mechanisms for crust formation. It was noted that another plausible mechanism would involve rising bubbles picking up particles during the transport. Other items noted were

- Density gradient data for DSTs do not support the mechanism for rise of a bubbly mass from the top of the nonconvective layer.

- The single bubble-particle situation will give the bounding case for the void content of the crust.

- The crust is not limited to the "buoyant" void fraction.

- Might be able to learn something from LOW data.

Blaine Barton noted that scans for A-101 did show some differences in the layers

- Two reasons for having different properties of crust material:

$>$ the material comes from the convective and nonconvective layers

$>$ it floats.

- The crust material may have a different crystal form than the same material in the nonconvective layer

- Need to be sure that all potential mechanisms for crust formation are considered. 


\section{Storage of Gas}

This was covered as part of the Phil Gauglitz presentation on crust formation. The gas could be as individual bubbles or connected bubbles.

\section{Discussion}

It was noted that if the crust were to dry out then that portion would not retain the gas. Data for A-101 have shown a relatively high amount of hydrogen in the first core sample. This would occur only if the crust were filled with fluid.

\section{Steady State Gas Release}

\section{Discussion}

No presentation was given; a short discussion was held on this subject. Mechanisms considered included diffusion, transport through channels/cracks, bubble migration (in the matrix), detachment of bubbles from particles, and transport of stable globs to the surface followed by slow release. Videos have shown many small areas that release bubbles, even though most of the waste surface shows a crust layer. It was noted that the minor openings could release a fairly large amount of gas.

\section{Spontaneous Release of Gas}

\section{Discussion}

It was the general consensus that a spontaneous release would be a "local" event rather than a "tank-wide" event. It could be similar to percolation in SST waste forms.

\section{Induced Gas Release}

\section{Discussion}

For normal operations such as core sampling, TC tree insertion, etc., a significant amount of gas would not be released in a short time period. It was noted that a large addition of water could cause a significant release of gas from the crust. Another item discussed involved a ring of gas at the wall, just under the crust. This idea was countered with the consideration that the crust would be thicker at the edge and thus any large bubble would tend to be near the central region. Consideration of large bubbles under the crust was an issue in 1990 but was dismissed as part of the extensive work done for SY-101. 


\section{Ignition of Gas Within the Crust}

Jerry Johnson gave a brief overview of the work planned at CIT. These tests would involve ignition of gas mixture in a tube that contains a bed of glass beads. After the tests with glass beads, some tests would be done with a porous ceramic and additions of fluid.

\section{Discussion}

Items raised included

- The test conditions must represent tank conditions. A crust with fully open pores, as in a bed of glass beads, would not contain hydrogen. The porous media must have fluid.

- Consider the use of "Aero-gels" for the porous media.

- Downward propagation should be considered instead of horizontal propagation.

- Do not use a mixture of hydrogen-nitrous oxide-air because the CIT data showed that $\mathrm{N} 2 \mathrm{O}$ was inert. Use hydrogen-air.

- Do sufficient homework to assure that such things as heat capacity of the media, the pore size, etc. will provide data that relates to the actual situation.

\section{Significance of "Crust" to Safety Issue}

\section{Discussion}

The presence and nature of the crust does not present an issue with respect to closure of the USQ but is part of the overall safety issue. It needs to be addressed as part of the resolution of the safety issue. Two issues to consider:

- The presence of a flammable gas boundary layer on top of the crust or just within it.

- The gradient of flammable gas within a partially salt-well pumped region. There may be a region of concern as the gas moves from the saturated layer through the drained layer to the top of the waste. 


\section{Potential Future Tests/Measurements}

\section{Discussion}

- Consider using the RGS to examine the gas content in a partially drained saltcake layer. (Note: this is being done in BY-101 and BY-109).

- Consider using the RGS to examine porosity in the crust. Do not extrude a sample, but slowly release the gas to one atm and then evaluate the porosity. A test similar to a "helium pycnometer" could be performed.

- Evaluate the nature and composition of crust particles with more refined techniques such as XRF, SEM, LEED.

- May want to consider a means to sample the crust so as not to alter it during the sampling. 


\section{Distribution}

No. of

Copies

Offsite

2 DOE Office of Scientific and

Technical Information

D. Campbell

102 Windham Road

Oak Ridge, TN 37830

C. W. Forsberg

Oak Ridge National Laboratory

P.O. Box 2008, MS-6495

Oak Ridge, TN 37831-6495

B. Hester

Westinghouse Savannah River Co.

Savannah River Site, $703 \mathrm{H}$

Aiken, SC 29802

B. C. Hudson

P.O. Box 271

Lindsborg, KS 67456

M. S. Kazimi

Massachusetts Institute of Technology

Department of Nuclear Engineering

77 Massachusetts Avenue

Cambridge, MA 02139

J. L. Kovach

P.O. Box 29151

70000 Huntley Road

Columbus, OH 43229

T. S. Kress

102-B Newridge Road

Oak Ridge, TN 37830
No. of

Copies

T. E. Larson

2711 Walnut St.

Los Alamos, NM 87545

3 W. L. Kubic

Los Alamos National Laboratory

P.O. Box 1663, MS K575

Los Alamos, NM 87545

D. Pepson

U.S. Department of Energy

Trevion II Building, EM-35

Washington, DC 20585-0002

Scott E. Slezak

806 Hermosa NE

Albuquerque, NM 87110

D. A. Powers

Sandia National Laboratories

MS-0744

Albuquerque, NM 87185-0744

Tony Valero

Washington Dept. of Ecology

1315 W. 4th

Kennewick, WA 99336

J. Tseng

U.S. Department of Energy

Trevion II Building, EM-35

Washington, DC 20585-0002

Onsite

5 DOE Richland Operations Office

C. A. Groendyke (3)

S7-54

G. W. Rosenwald

S7-54

D. H. Irby

S7-54 
No. of

Copies

34 Hanford Contractors

S. A. Barker

R2-11

W. B. Barton

R. E. Bauer

T. R. Benegas

J. R. Biggs

D. R. Bratzel

M. L. Carlisle

R. J. Cash

J. M. Conner

C. Defigh-Price

T. C. Geer

J. M. Grigsby

B. K. Hampton

C. E. Hanson

D. L. Herting

K. M. Hodgson

J. W. Hunt

G. D. Johnson (5)

K. N. Jordan

N. W. Kirch

J. R. Kristofzski

D. C. Larsen

J. W. Lentsch

R. M. Marusich

J. C. Person

M. A. Payne

J. A. Poppiti

R. E. Raymond

D. A. Reynolds

F. A. Schmorde

L. M. Stock

R2-11

S7-73

S7-73
No. of

Copies

42 Pacific Northwest National Laboratory

R.T. Allemann

K7-15

G1-54

H7-07

K7-07

S7-73

R2-11

R2-12

R2-38

S7-73

S7-40

G1-54

T6-09

$\mathrm{H} 0-34$

R2-12

S7-73

R3-72

R2-11

R2-12

T4-08

S2-48

B4-47

T6-07

R2-58

S7-54

R2-38

R2-11

S7-01

S7-73
Z. I. Antoniak

J. M. Bates

S. Q. Bennett

S. A. Bryan

P. R. Bredt

J. W. Brothers (3)

G. Chen

P. A. Gauglitz (10)

J. L. Huckaby

L. A. Mahoney

D. P. Mendoza

P. A. Meyer

L. M. Peurrung

S. D. Rassat (10)

L. A. Schienbein

C. W. Stewart

Information Release (5)
K7-15

K7-15

K7-90

P7-25

P7-25

K9-20

K5-12

K6-28

K6-80

K7-15

K6-28

K7-15

K6-28

K6-28

K5-20

K7-15

K1-06 